TAO, Vol. 15, No. 5, 759-784, December 2004

\title{
Long-Range Transport of Asian Dust and Air Pollutants to Taiwan
}

\author{
Chuan-Yao Lin ${ }^{1}{ }^{1}$, Shaw Chen Liu ${ }^{1}$, Charles C.-K. Chou ${ }^{1}$, Tsun Hsien Liu ${ }^{1}$, Chung-Te Lee ${ }^{2}$, \\ Chung-Shin Yuan ${ }^{3}$, Chein-Jung Shiu ${ }^{4}$, and Chea-Yuan Young ${ }^{5}$
}

(Manuscript received 15 April 2004, in final form 26 October 2004)

\begin{abstract}
Dust storms and long-range transport of pollutants are major environmental concerns of Taiwan during the winter monsoon season when northeasterly winds prevail following passages of cold fronts. To quantify the impact on air quality, we develop an objective method to classify and study the long-range transport processes by examining the frontal passages in two representative years. We have found that there is about one frontal passage per week in winter and spring, consistent with the climatological average. The long-range transport events are classified into three types according to their degrees of impact on levels of dusts and air pollutants in Taiwan, namely dust storms (DS), long-range transport with pollutants (FP), and long-range transport of background air masses (BG). DS cases occurred $4.7 \%$ of the time over 14 months and had a large average $\mathrm{PM}_{10}$ concentration of $127.6 \mu \mathrm{g} \mathrm{m}^{-3}$ at Wan-Li station. FP cases occurred $1.9 \%$ of the time and the mean concentration of $\mathrm{PM}_{10}$ during the FP periods was about $85 \mu \mathrm{g} \mathrm{m}^{-3}$. BG cases happened $18.6 \%$ of the time and the mean concentration of $\mathrm{PM}_{10}$ was $32.8 \mu \mathrm{g} \mathrm{m}^{-3}$. Dust storms and air pollutants tend to be transported in different air parcels as evidenced by a lack of correlation between dust aerosols and air pollutants. The frequency of local pollution (LP) cases was $71.7 \%$ in winter and spring. The average $P_{10}$ concentration of LP cases at the Wan-Li station was $47.4 \mu \mathrm{g} \mathrm{m}^{-3}$. However, about one to two-thirds of the $\mathrm{PM}_{10}$ during LP cases can be attributed to the long-
\end{abstract}

${ }^{1}$ Research Center for Environmental Change, Academia Sinica, Taipei, Taiwan, ROC

2 National Central University, Chung-Li, Taiwan, ROC

${ }^{3}$ National Sun Yan-Sen University, Kaohsiung, Taiwan, ROC

4 Department of Atmospheric Sciences, National Taiwan University, Taipei, Taiwan, ROC

${ }^{5}$ Environmental Protection Administration, Taipei, Taiwan, ROC

* Corresponding author address: Dr. Chuan-Yao Lin, Research Center for Environmental Change, Academia Sinica, Taipei, Taiwan, ROC;E-mail: yao435@rcec.sinica.edu.tw 


\begin{abstract}
range transport. When this contribution is taken into account, we estimate that the contribution of long-range transport to $\mathrm{PM}_{10}$ abundance in northern Taiwan during winter and spring to be in the range of $50 \%$ to $75 \%$.
\end{abstract}

\author{
(Key words: Dust storm, Air pollutant, Aerosol, Long-range transport)
}

\title{
1. INTRODUCTION
}

Dust storms are common during late winter and spring in East Asia (Shaw 1980; Duce et al. 1980; Wan et al. 1982; Parrington et al. 1983; Chen and Chen 1987; Prospero et al. 1989; Wang et al. 2000; Lin T. H. 2001; Chun et al. 2001; Murayama et al. 2001). They originate in arid and semi-arid regions in northern China, Mongolia, and Central Asia under high surface wind conditions (e.g., Duce et al. 1980.). Chen and Chen (1987) showed that strong surface winds and low humidity in the lower troposphere associated with cold fronts over arid areas of China or Central Asia in the spring are the conditions most conducive to the generation of Asian dust storms.

Taiwan is an island in the subtropics, located off the southeast coast of China. Its climate is strongly affected by the circulation of monsoons over East Asia. During winter and spring, as part of the winter Asian monsoon, the Siberian high dominates the weather pattern of East Asia. The main source region of anticyclones lies nearly stationary around Mongolia throughout the winter (e.g., Wang 1974). The major track of anticyclones in this season extends from the source region southeastward passing the lower part of the Yellow River, then eastward through the Yellow Sea, Korean Peninsula, and then to Japan. As the winter progresses, this major track shifts southeastward to the coast of the East China Sea.

The frontal zone is characterized by a strong temperature gradient and a shift in wind direction. Figure 1 shows a typical 3-day back trajectory of a frontal passage that passes over northern Taiwan. The air masses originate at an altitude $3 \mathrm{~km}$ above the dust source regions of western China and also pass over the industrial regions of eastern China. This allows air mass to pick up air pollutants if vertical mixing is favorable to such entrainment. In which case, air pollutants and dust can be transported to Taiwan. However, in a subsiding high-pressure system atmospheric stability tends to be high and prevents effective vertical mixing. These processes are very important to long-range transport of dust and air pollutants and are a major focus of this study.

Stagnant and sunny conditions are typical prior to a frontal passage in Taiwan. In addition, there is a clear diurnal temperature pattern with a daytime maximum. Under these conditions, local emissions are the major source of air pollution in Taiwan. After the frontal passage, surface temperatures drop rapidly, and relatively strong northeasterly winds prevail which can transport dust and air pollutants from the Asian continent to Taiwan. The cold temperature and northeasterly winds usually last for about two days before it starts to warm up with the return of the diurnal temperature pattern. These anticyclones associated with the front system frequently form at a rate of about one per week (e.g., Bachmeier et al. 1996).

Many researchers noted that not only mineral dust but also air pollutants were carried 
over long distances in the spring over eastern Asia and the Pacific Ocean (Uematsu et al. 1983; Prospero et al. 1985; Prospero and Savoie 1989; Okada et al. 1990; Harris et al. 1992; Uemastu et al. 1992; Arimoto et al. 1996; Jaffe et al. 1997; Xiao et al. 1997; Liu and Shiu 2001; Uematsu et al. 2002; Uno I. et al. 2003 ). Recently, Prospero et al. (2003), in a study of aerosols distributions at Midway Island during 1981-2000, found that pollutants such as sulfate and nitrate ions in the aerosols increased concurrently with mineral dust in spring and winter. In addition, they showed that anthropogenic sulfate and nitrate concentrations in aerosols almost doubled from 1981 to the mid 1990s, mainly because of increased emissions from China.

However, little correlation between air pollutants and Asian dust storms is found in our analysis of hourly measurements at the Taiwan Environment Protection Administration (TEPA) air quality monitoring stations. We notice that concentrations of air pollutants such as $\mathrm{CO}$, $\mathrm{NO}_{\mathrm{X}}$ and $\mathrm{SO}_{2}$ during a typical Asian dust storm tend to stay at background or moderate values most of the time and elevated values are found only occasionally. Actually, as we will see later that most of the frontal passages over Taiwan have background/moderate levels of air pollutants. This is probably a result of a well-mixed boundary layer over the East China Sea upwind of Taiwan, which is known for highly efficient turbulence mixing because of the cold winter monsoon winds over the relatively warm Kuroshio Current.

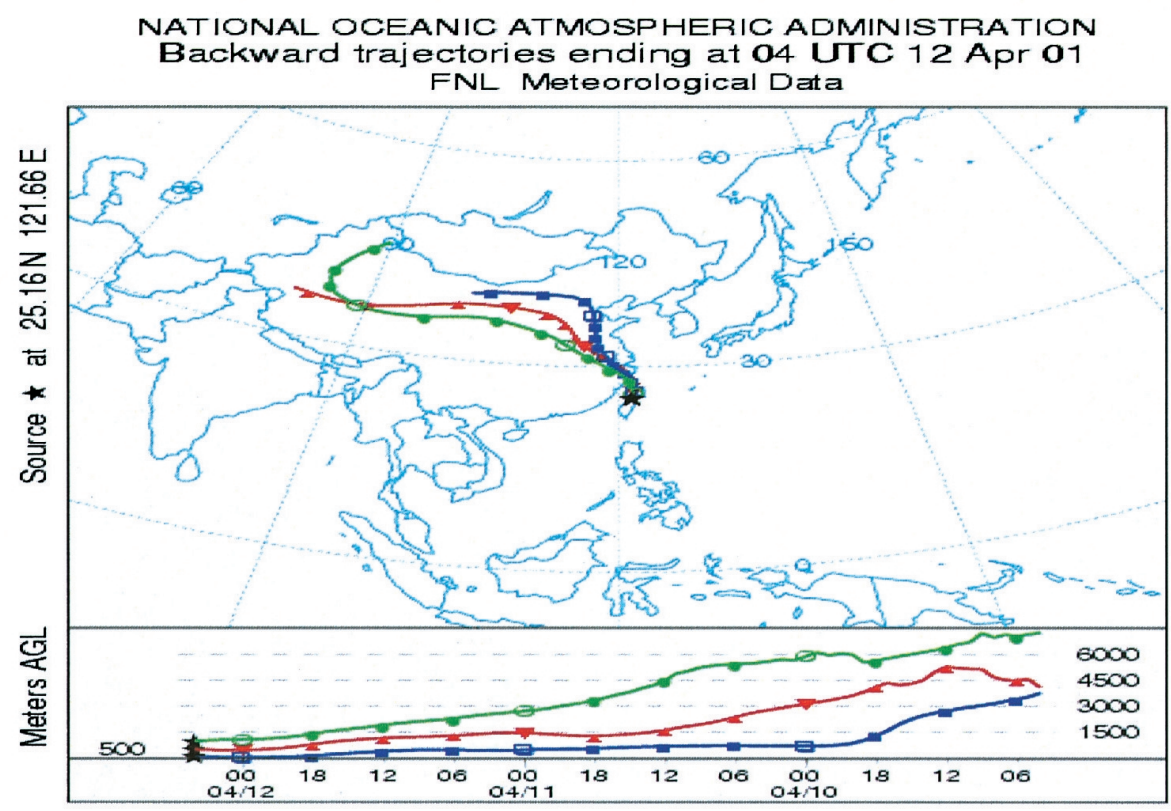

Fig. 1. Result of the HYSPLIT model 3-day backward trajectory analysis started at 0400UTC (1200LST), April 12, 2001 at altitudes of 100, 500 and $1000 \mathrm{~m}$ at Wan-Li station in northern Taiwan. The top and bottom panels display horizontal and vertical motion. Symbols denote the location of the air parcel every 6 hours. 
The lack of correlation between mineral dust and air pollutants in TEPA measurements is most likely because of the fact that mineral dust and air pollutants originate from different source regions (Fig. 1). Air masses containing dust that pass over industrial areas may be at altitudes too high to mix with pollutants near the surface. In order to better understand this problem and, more importantly, the key processes in the long-range transport of dust and air pollutants, we conduct this study analyzing concurrent measurements of aerosols, trace gases, and meteorological parameters in Taiwan. We focus on the frontal passages and develop an objective method to classify various types of long-range transport according to dust and air pollutant levels. Finally, we evaluate the contribution of long-range transport to distributions of $\mathrm{PM}_{10}$ in northern Taiwan.

\section{DATA ANALYSIS METHOD}

Meteorological parameters, i.e., surface temperature, wind direction and speed, rainfall, and atmospheric concentrations of $\mathrm{PM}_{10}, \mathrm{NO}_{\mathrm{X}}, \mathrm{CO}$, and $\mathrm{SO}_{2}$ observe at coastal stations and a mountain station in northern Taiwan are used in this study. The coastal stations Wan-Li, Tan-Shui, and I-Lan (Fig. 2) along north and northeast Taiwan are major stations used in the data analysis. These stations are on the upwind direction of the frontal passage and thus ideal for observing the effect of frontal passages on distributions of dust and air pollutants. Measurements at the Yang-Ming mountain station (altitude $826 \mathrm{~m}$ ) at a national park in northern Taiwan turn out to be very valuable also because it is relatively clean and provides information on altitudinal distribution of trace species. The tall north-to-south running Central Mountain Range (average altitude $2.5 \mathrm{~km}$ ) in Taiwan effectively protects southern Taiwan from the winter monsoon, making the data there difficult to interpret.

In this work, we develop an objective method to classify the air mass following each frontal passage in northern Taiwan according to the amounts of long-range transported dust and air pollutants. The meteorological parameters observed near the coasts such as temperature and winds can be used to identify the time and intensity of the frontal passage. As discussed in the introduction, air mass behind a front usually contains Asian continental air (Fig. 1), while winds before the frontal passage tend to be weak and thus local emissions can dominate distributions of air pollutants. For contrast purposes, analysis starts one day before the frontal passage and lasts for four days to cover the entire period of a typical cold front passage.

We show below that Asian continental air behind a front can be further classified into three categories: (1) the dust storm case (denoted DS) that consists primarily of Asian mineral dust but not necessarily air pollutants as mentioned earlier; (2) the frontal pollution case (denoted FP) that contains a significant amount of air pollutants from the Asian continent (i.e., longrange transport of air pollutants) but little dust; and (3) the background air case (denoted BG) that contains relatively clean background air from the East China Sea north of Taiwan. When there is no frontal passage, the fair weather diurnal variation of temperature becomes apparent and concentrations of air pollutants clearly follow local temporal emission patterns. This case is classified as local pollution (denoted LP). 


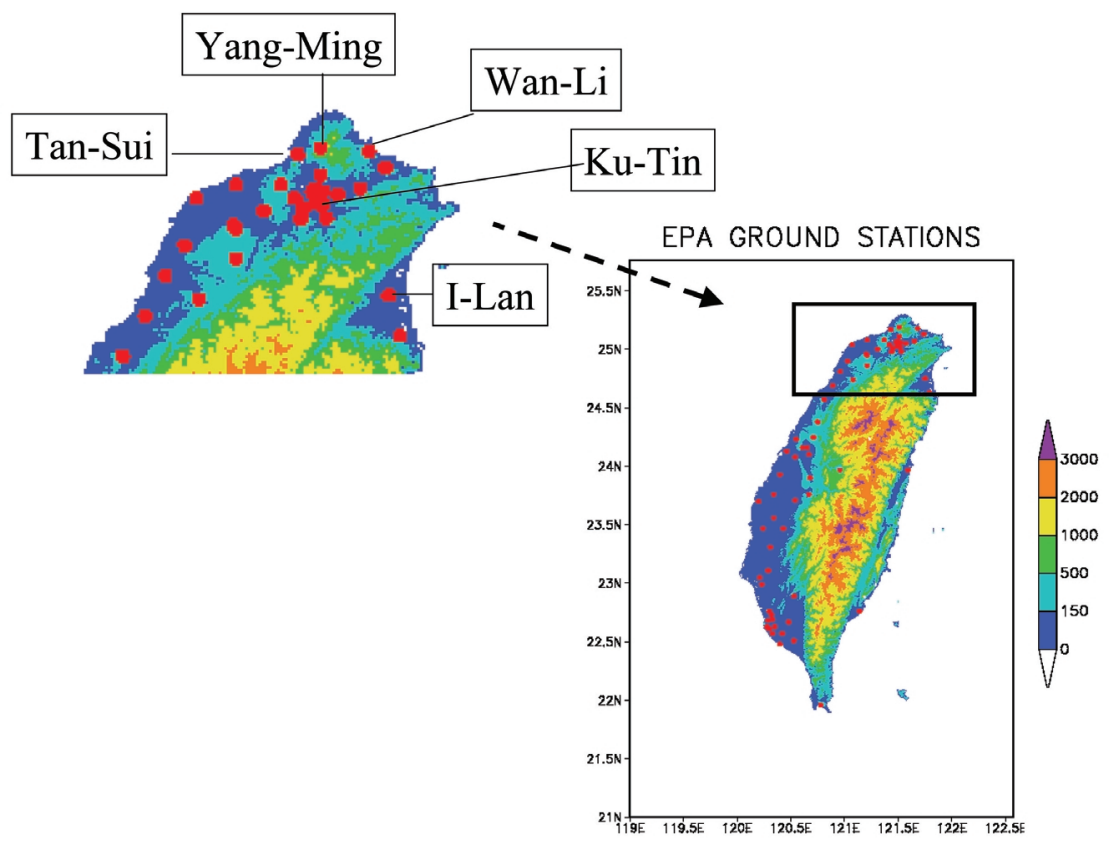

Fig. 2. The topography (altitude is represented by shadowed areas) and EPA ground stations (closed circles) of air quality network in northern Taiwan.

\section{DATA USED}

We use hourly meteorological data and concentrations of $\mathrm{PM}_{10}$ and other pollutant measured at TEPA air quality monitoring stations. Since the frontal passage is a typical weather event in Taiwan in winter and spring, a large number of episodes are identified from November 1999 to May 2000, and from November 2000 to May 2001. These two years are chosen because the data are readily available and representative of climatological mean.

\section{CLASSIFICATION OF AIR MASSES}

\subsection{Local Pollution Cases}

In Taiwan, high-pressure fair weather in winter usually prevails between two frontal passages. It is characterized by weak surface winds, stable atmospheric conditions, and a clear diurnal cycle in surface temperature. Stable and weak wind conditions are conducive to the accumulation of air pollutants due to local emissions. Figure 3 shows a typical local pollution episode (Jan. 17 - 20, 2001) at Wan-Li station. Synoptic-scale analysis (Fig. 4) shows a high pressure system controlled the weather pattern around Taiwan. Concentrations of pollutants consistently show temporal variations with peaks around rush hour. This is a clear case domi- 


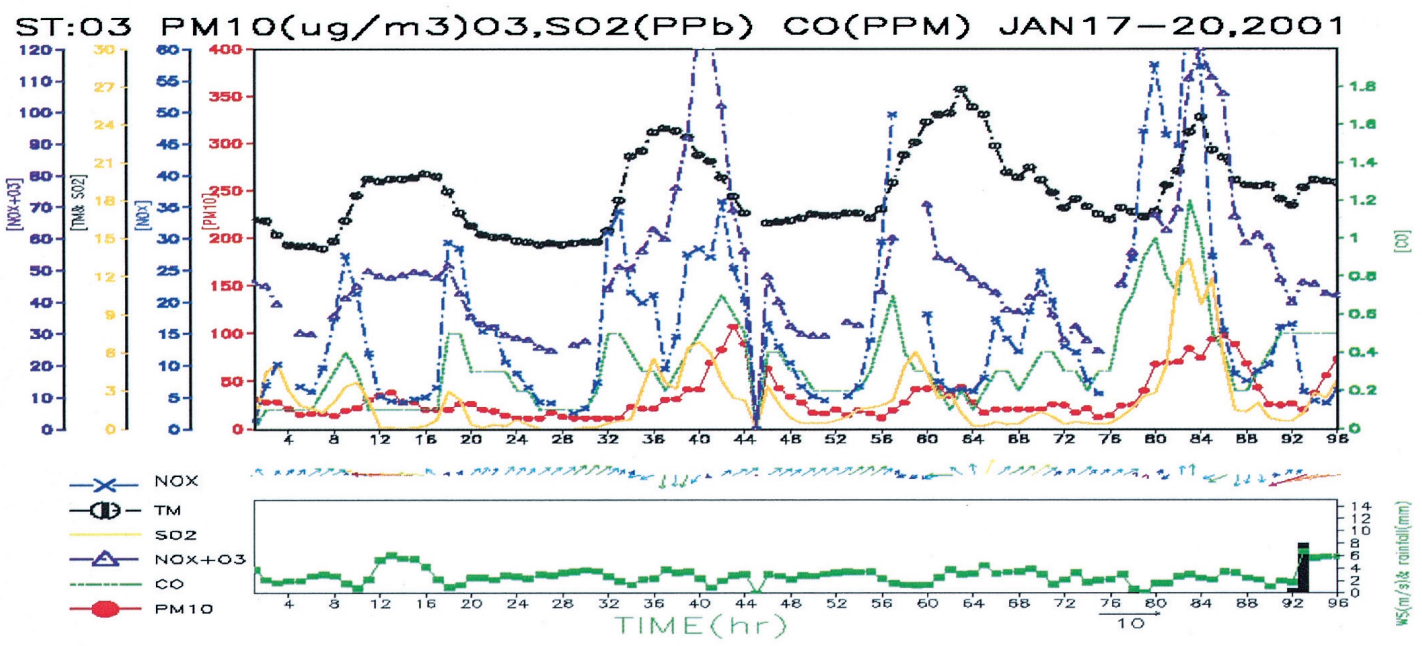

Fig. 3. The time series of hourly $\mathrm{PM}_{10}$ (red closed circles), $\mathrm{CO}$ (dashed line), $\mathrm{SO}_{2}$ (solid), $\mathrm{NO}_{\mathrm{X}}+\mathrm{O}_{3}$ (triangle), $\mathrm{NO}_{\mathrm{X}}$ (cross), surface temperature (open circle with vertical line), wind speed (closed squares, bottom panel) and rainfall (black bar, bottom panel) are shown at Wan-Li station during a local pollution case (0100LST Jan. 17 to 2400LST Jan. 20, 2001). Surface wind at Wan-Li station is represented by wind vector.

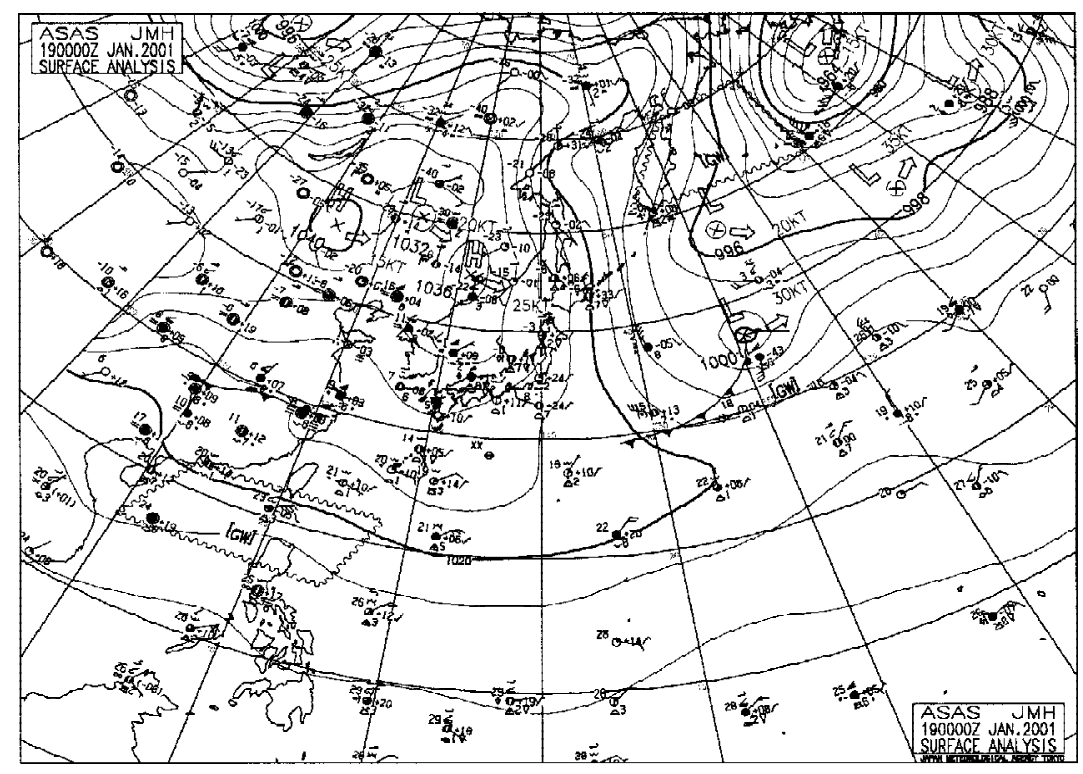

Fig. 4. Synoptic-scale surface weather map at 0000Z (0800LST) Jan. 19, 2001. 
nated by local pollution (LP). In the daytime, anthropogenic emissions at rush hour lead to the concurrent enhancement of air pollutants such as $\mathrm{NO}_{\mathrm{X}}, \mathrm{CO}$, and $\mathrm{SO}_{2} \cdot \mathrm{PM}_{10}$ concentrations show similar patterns but with some phase lag, probably as a result of a secondary source. At night, concentrations of all pollutants drop gradually to their minima. $\mathrm{PM}_{10}$ concentrations generally stay below $100 \mu \mathrm{g} \mathrm{m}^{-3}$ and the correlation between $\mathrm{PM}_{10}$ and other air pollutants are poor on an hourly basis. However, on a time scale of a half day or longer, a positive correlation is apparent.

In order to identify sources and to examine how transport paths affect concentrations of air pollutants in northern Taiwan, a three-day backward trajectory analysis is preformed for each air-mass case. The analysis was computed using the HYSPLIT (Hybrid Single-Particle Lagrangian-Integrated Trajectory) model (Draxler and Hess 1998). A backward trajectory analysis was performed for altitudes of 100,500 , and $1000 \mathrm{~m}$, at Wan-Li station in northern Taiwan.

The trajectory analysis started from 0400UTC (1200LST), on Jan. 20, 2001 (Fig. 5). The backward trajectories show slow-moving air parcels around the western Pacific over a 72hour period prior to 0400UTC. Weak winds and clean oceanic air enable local emissions to

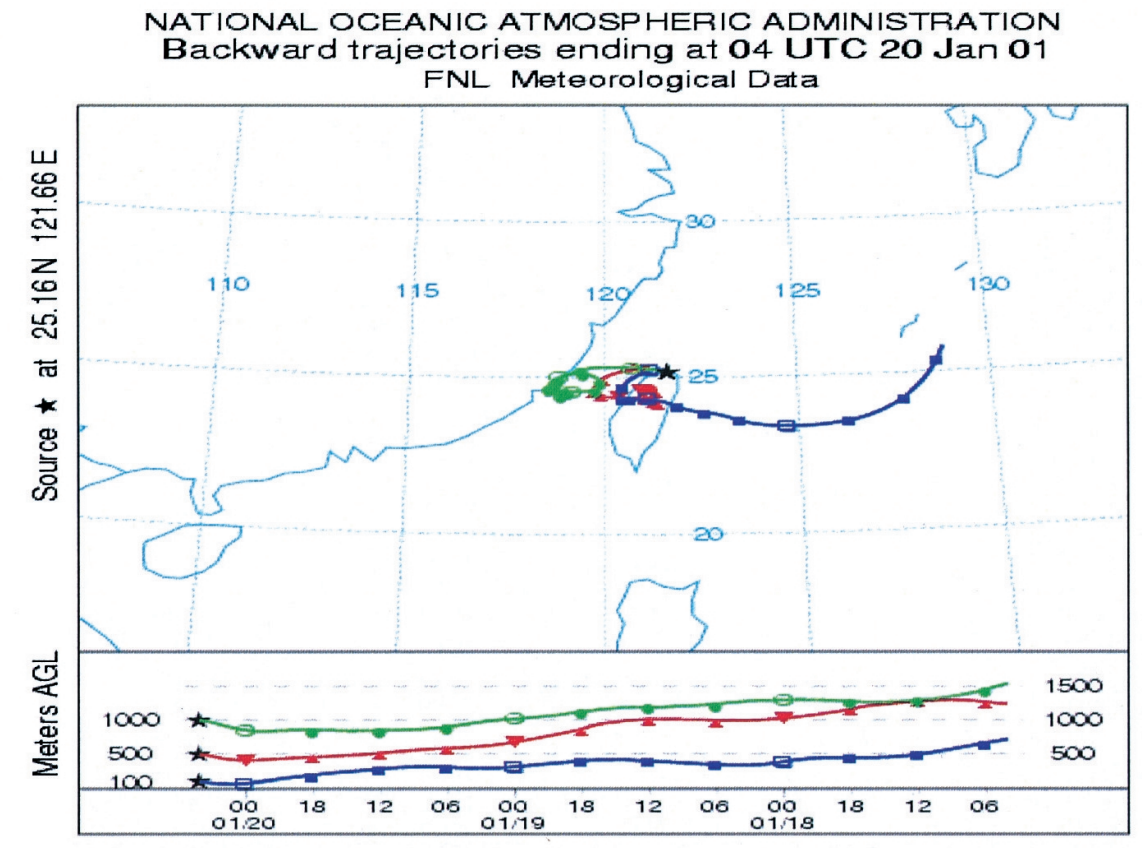

Fig. 5. Result of the HYSPLIT model 3-day backward trajectory analysis started at 0400UTC (1200LST) Jan. 20, 2001 at altitudes of 100, 500 and $1000 \mathrm{~m}$ at Wan-Li station in northern Taiwan. The top and bottom panels display horizontal and vertical motion. Symbols denote the location of the air parcel every 6 hours. 
dominate air quality. The sunny, stagnant conditions of a high-pressure system also lead to a typical fair weather diurnal temperature distribution.

\subsection{Long-range Transport}

As mentioned earlier, significant long-range transport is usually associated with a frontal passage that is characterized by a strong pressure gradient at the surface and a cold air mass behind it. As the cold front passes over northern Taiwan, the surface temperature drops to a minimum, wind speed increases to a maximum and the wind changes to a northeasterly direction. The strong winds sweep away most of the local pollutants such that the diurnal variations of pollutants observed in LP cases become less evident or even disappear all together. In this situation, most of the enhancement of air pollutants can be attributed to long-range transport.

Based on measurements of $\mathrm{PM}_{10}$ and other air pollutants at TEPA air quality ground stations, we show below that the long-range transport associated with frontal passages can be further classified into three types, namely dust storm (DS), long-range transport with pollutants (FP), and long-range transport of background air masses (BG).

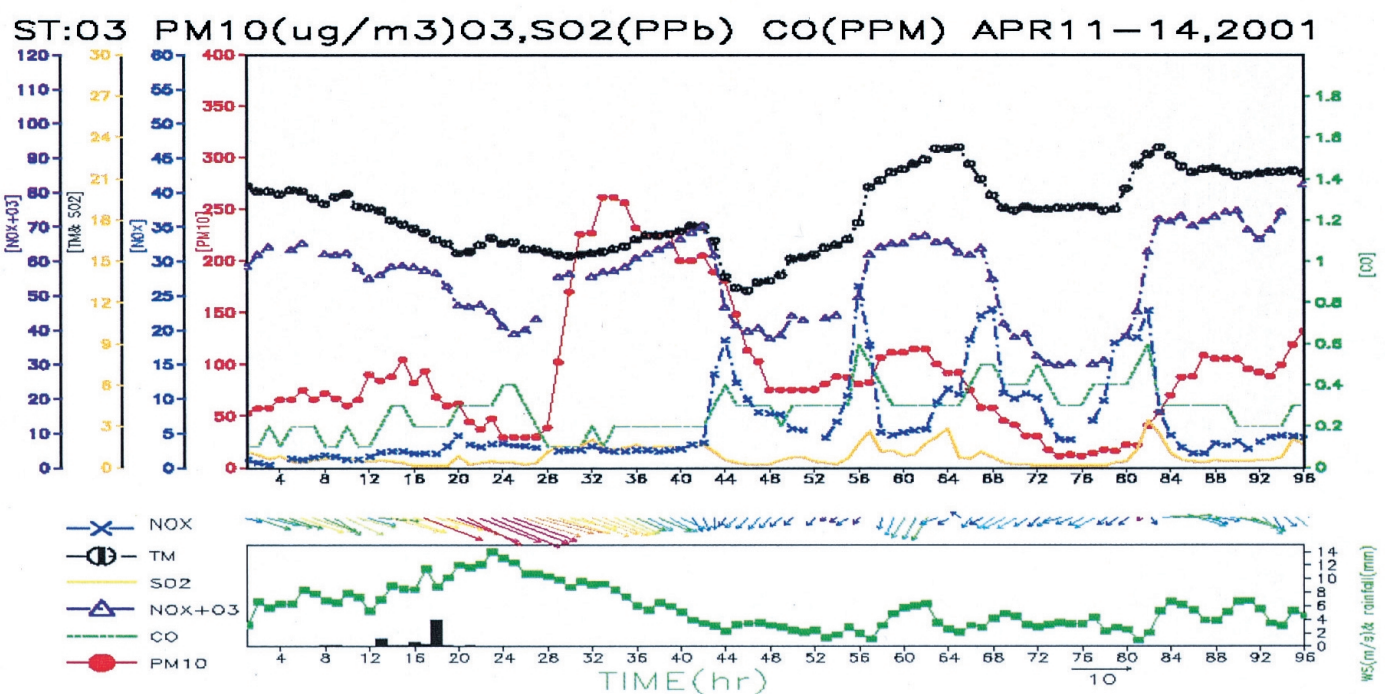

Fig. 6. The time series of hourly $\mathrm{PM}_{10}$ (red closed circles), $\mathrm{CO}$ (dashed line), $\mathrm{SO}_{2}$ (solid), $\mathrm{NO}_{\mathrm{X}}+\mathrm{O}_{3}$ (triangle), $\mathrm{NO}_{\mathrm{X}}$ (cross), surface temperature (open circle with vertical line), wind speed (closed square, bottom panel) and rainfall (black bar, bottom panel) are shown at Wan-Li station (0100LST April 11 to 2400LST April 14, 2001). Surface wind at WanLi station is represented by wind vector. 


\subsubsection{Dust Storm Cases}

Figure 6 shows a typical dust storm event observed at Wan-Li station on April 12 - 13, 2001. The data and synoptic weather map (Fig. 7) indicate that the cold front arrived around midnight of April 11, 2001. The wind speed reached a maximum when temperature reached a minimum on April 12, 2001. Meanwhile, $\mathrm{PM}_{10}$ concentrations dropped to near the detection limit and then jumped drastically to about $250 \mu \mathrm{g} \mathrm{m}^{-3}$ in a few hours. These concentrations of $\mathrm{PM}_{10}$ were almost two or three times the normal level for LP cases. In fact, elevated concentrations of $\mathrm{PM}_{10}$ with peak values of about $200 \mu \mathrm{g} \mathrm{m}^{-3}$ were observed over most stations in

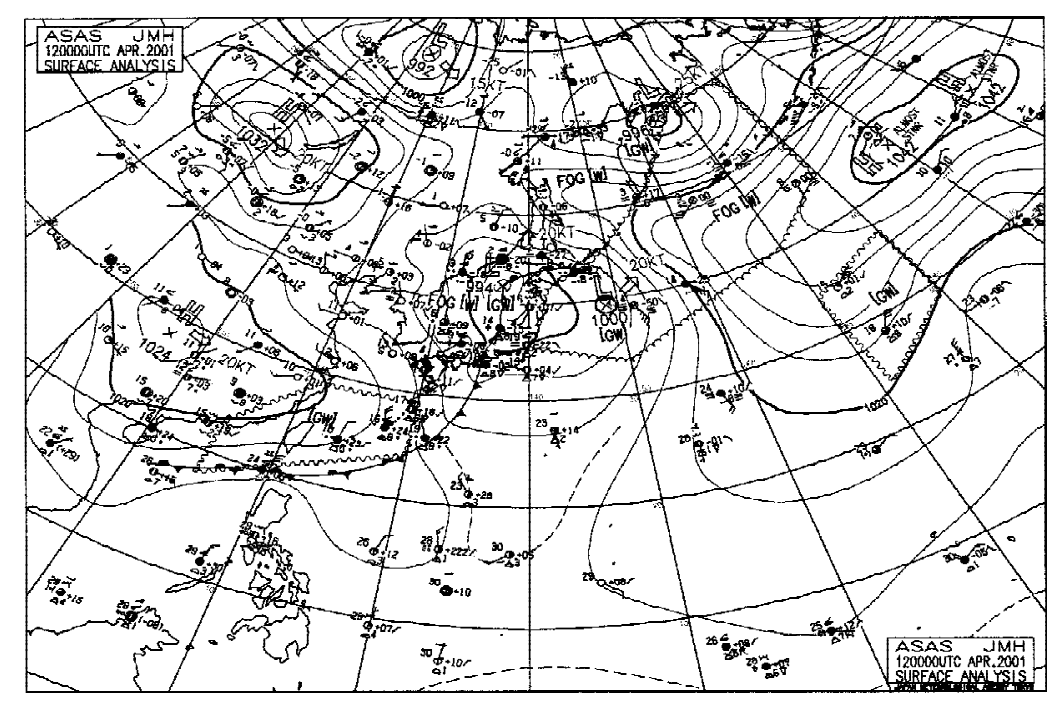

Fig. 7. Synoptic-scale surface analysis at 0000Z (0800LST) April 12, 2001.

Taiwan on April 12 and 13, 2001. On April 12, the prevailing winds were relatively strong, especially at the Wan-Li station. Strong winds swept away most of the local pollutants as evidenced by the fact that $\mathrm{NO}_{\mathrm{X}}, \mathrm{CO}$, and $\mathrm{SO}_{2}$ stayed at extremely low values and showed no diurnal cycle. Mineral dust dominated the composition of $\mathrm{PM}_{10}$ (Shu et al. 2004; Wang et al. 2004).

There were very few air pollutants carried with the dust storm even though the back trajectory passes over the industrial regions of northern China (see next section). The correlation coefficients between $\mathrm{PM}_{10}$ and other air pollutants (e.g., $\mathrm{CO}$ and $\mathrm{SO}_{2}$ ) are very low as expected (Figs. 8a, b). Thus, we can conclude that the $\mathrm{PM}_{10}$ at Wan-Li on April 12, 2001 was from a dust storm carrying few air pollutants. On the next day (April 13), rush hour peaks of $\mathrm{NO}_{\mathrm{X}}, \mathrm{CO}$, and $\mathrm{SO}_{2}$ were observed near the $56^{\text {th }}$ and $68^{\text {th }}$ hours of Fig. 6 as a result of local emissions when surface winds weakened and the normal fair day diurnal cycle in temperature returned. April 13, 2001 was classified as an LP even though some of the $\mathrm{PM}_{10}$ (up to about 
(a)

(b)
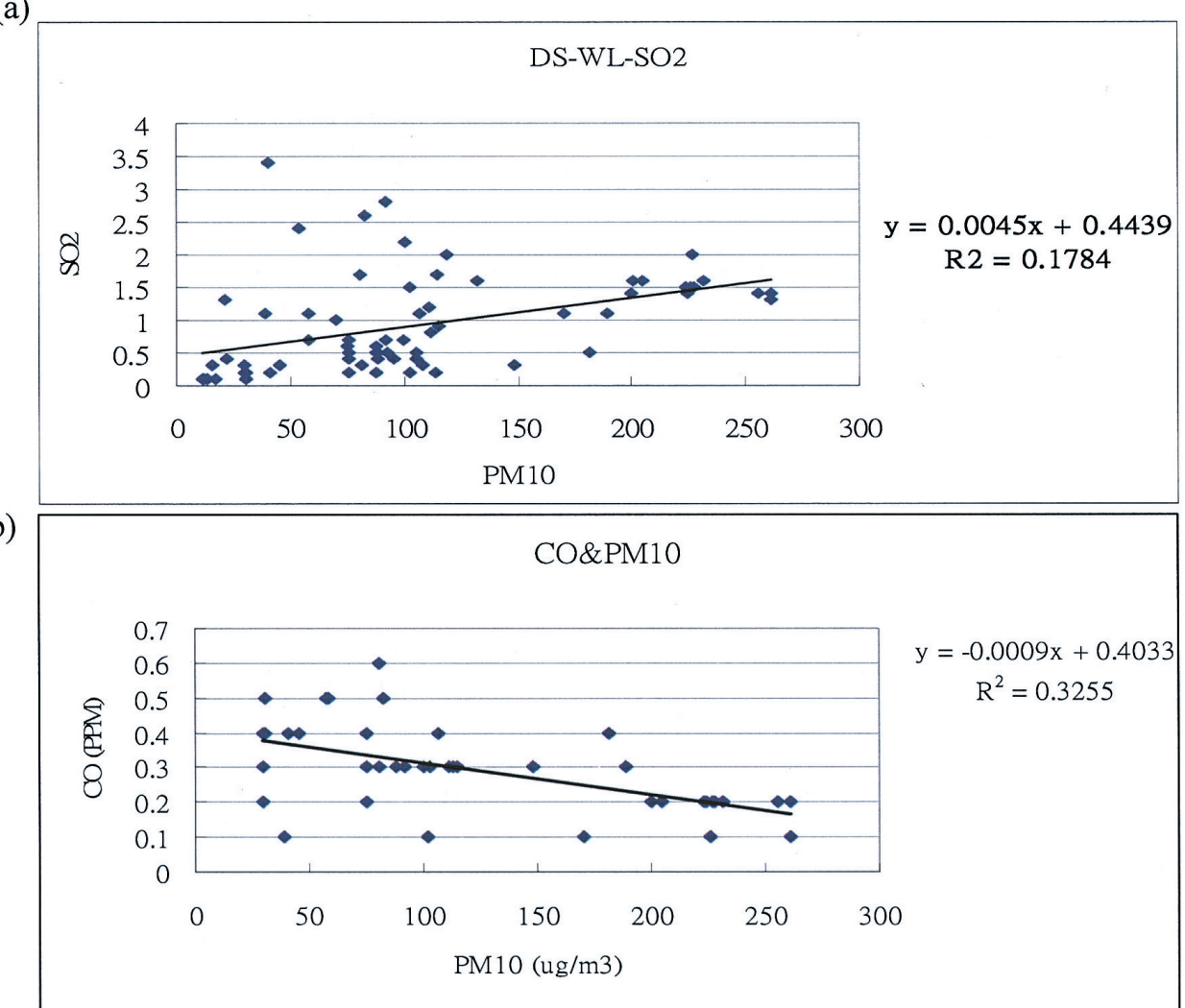

Fig. 8. Relationship between (a) $\mathrm{PM}_{10}$ and $\mathrm{SO}_{2}$ (b) $\mathrm{PM}_{10}$ and $\mathrm{CO}$ during (0100LST April 12 to 2400LST April 13, 2001 at Wan-Li station).

$70 \mu \mathrm{g} \mathrm{m}^{-3}$ ) was definitely leftover dust from the previous day.

72-hour back-trajectory analyses at altitudes of 100, 500, and $1000 \mathrm{~m}$ calculated for the DS case of April 12, 2001 (Fig. 1) suggest that the air mass in northern Taiwan originated from dust source areas near Mongolia and western China. The trajectory of air parcels originated at high altitude (above $3 \mathrm{~km}$ ) in northern China, following a typically subsiding high-pressure system to Taiwan.

Figure 9 shows another DS case on Feb. 1, 2001. Surface wind speed increased to its maximum in the early morning of Feb. 1, 2001 with $\mathrm{PM}_{10}$ and other air pollutants increased concurrently. The correlations between $\mathrm{PM}_{10}$ and other air pollutants during this period were very good. However, when the $\mathrm{PM}_{10}$ level reached its maximum value of about $150 \mu \mathrm{g} \mathrm{m}^{-3}$ at 1500LST, concentrations of other air pollutants dropped substantially and stayed low thereafter. It is obvious that after 1500LST correlations between $\mathrm{PM}_{10}$ and other air pollutants on an hourly basis were poor. The trajectories of air parcels at 500 and $1000 \mathrm{~m}$ came from dust 


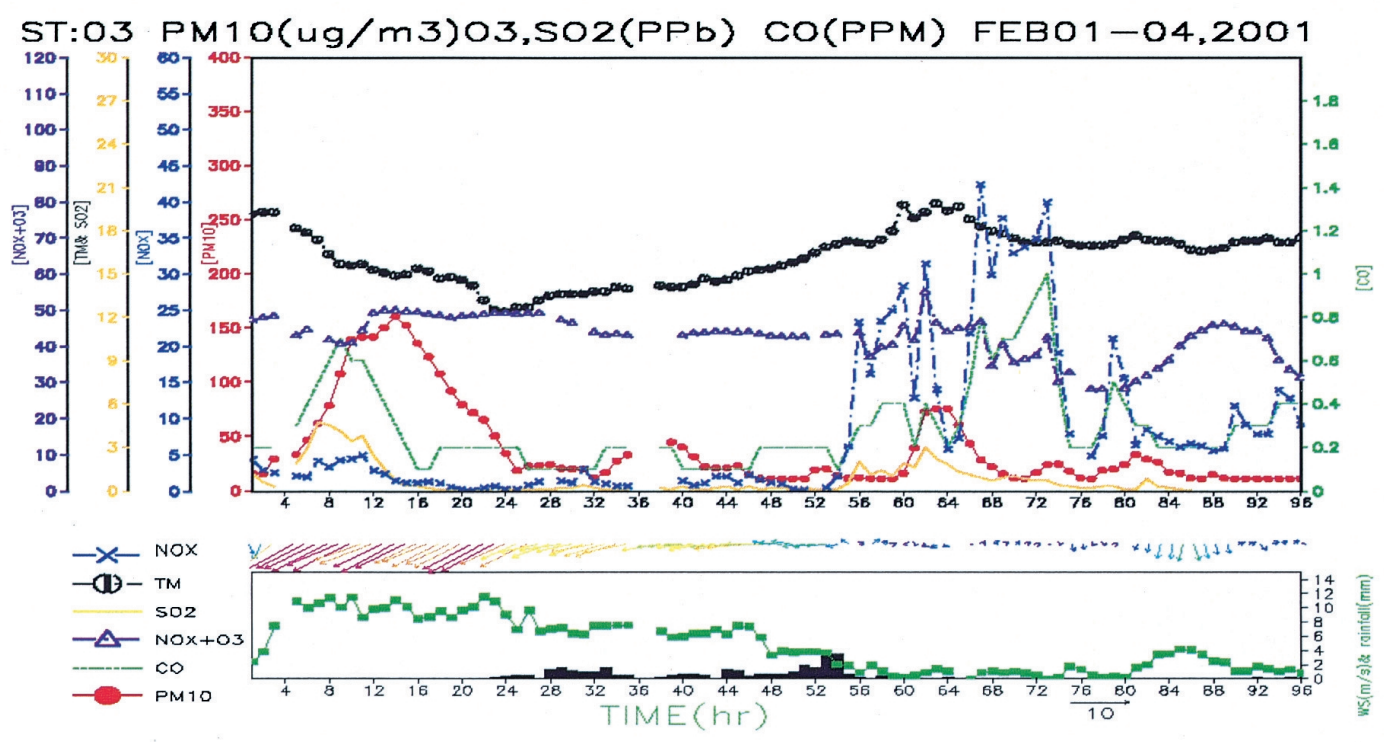

Fig. 9. The time series of hourly $\mathrm{PM}_{10}$ (red closed circles), $\mathrm{CO}$ (dashed line), $\mathrm{SO}_{2}$ (solid), $\mathrm{NO}_{\mathrm{X}}+\mathrm{O}_{3}$ (triangle), $\mathrm{NO}_{\mathrm{X}}$ (cross), surface temperature (open circle with vertical line), wind speed (closed square, bottom panel) and rainfall (black bar, bottom panel) are shown at Wan-Li station during a dust storm case (0100LST Feb. 1 to 2400LST Feb. 4, 2001). Surface wind at Wan-Li station is represented by wind vector.

source areas in central China (Fig. 10). However, the air parcel at $100 \mathrm{~m}$ originated at low elevation in the industrial areas near Shanghai which probably contribute significant air pollutants to the air parcel.

In this DS case, the dust storm apparently picks up air pollutants in the first few hours, but remains relatively clean afterward. In fact, in our examination of various individual dust storms we notice that they only occasionally carry significant amounts of air pollutants, and only during certain periods of a dust storm. Apparently dust storms pick up air pollutants along their long-range transport to Taiwan only when the atmospheric stability and vertical mixing conditions over polluted regions are favorable to the entrainment of pollutants from the surface layer.

\subsubsection{Frontal Passages with Pollutants}

Figure 11 shows a case in which a frontal passage (Fig. 12) is accompanied by a substantial pickup of air pollutants. It shows that northeasterly winds with maximum speed of about $12 \mathrm{~m} \mathrm{~s}^{-1}$ brought an air mass from the East China Sea with $\mathrm{PM}_{10}$ concentrations that peaked 


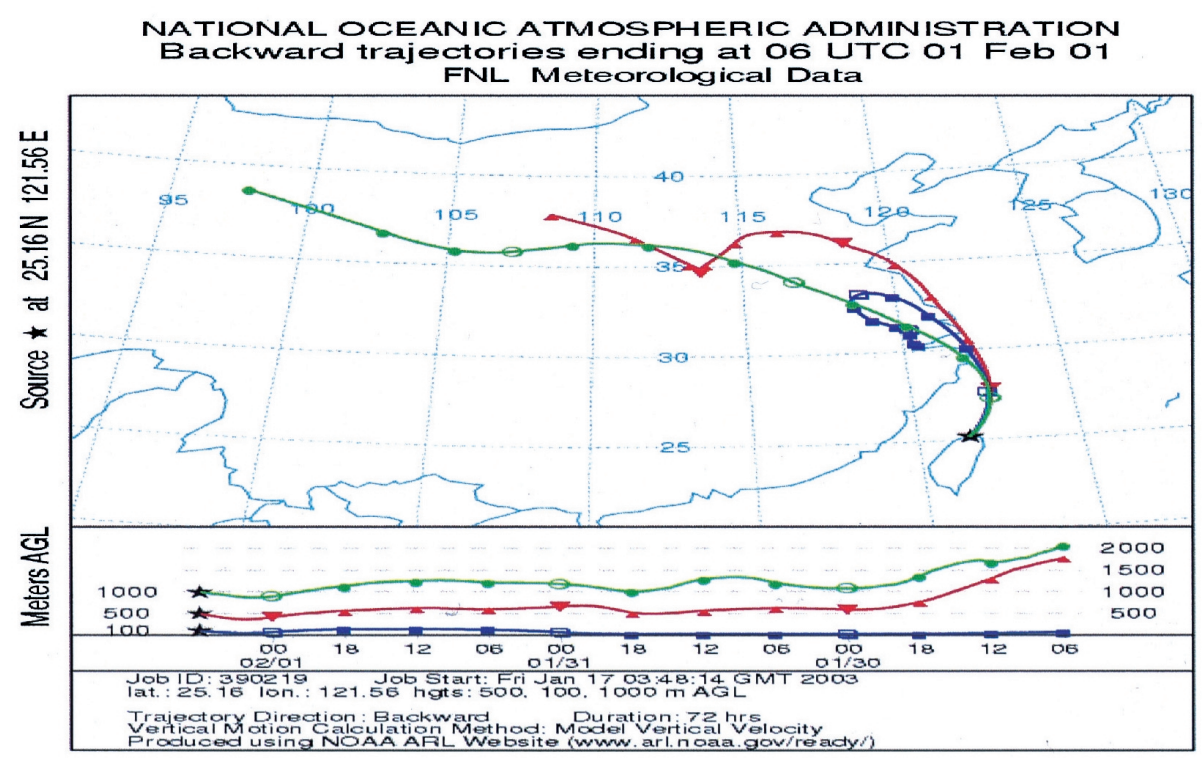

Fig. 10. Result of the HYSPLIT model 3-day backward trajectory analysis started at 0600UTC (1400LST), Feb. 1, 2001 at altitudes of 100, 500 and $1000 \mathrm{~m}$ at Wan-Li station in northern Taiwan. The top and bottom panels display horizontal and vertical motion. Symbols denote the location of the air parcel every 6 hours.

at about $100 \mu \mathrm{g} \mathrm{m}^{-3}$ on Jan. 19, 2000 (Fig. 11). The concentrations of $\mathrm{PM}_{10}, \mathrm{CO}$, and $\mathrm{SO}_{2}$ were well correlated, suggesting that pollutants were the major component of the $\mathrm{PM}_{10}$. Furthermore concentrations of $\mathrm{PM}_{10}, \mathrm{CO}$, and $\mathrm{SO}_{2}$ did not show any diurnal cycle and thus unlikely to be from local emissions. In fact, the Yang-Ming mountain station (Fig. 13a) and the Tan-Shui costal station (Fig. 13b) had nearly identical concentrations of $\mathrm{PM}_{10}, \mathrm{CO}$, and $\mathrm{SO}_{2}$ as the Wan-Li station on Jan. 19, 2000. This was strong evidence that the pollutants came from upstream source areas and that the levels of $\mathrm{CO}$ and $\mathrm{SO}_{2}$ were controlled by long-range transport rather than local emissions.

Figure 14 shows the 72-hour backward trajectory starting from 0400UTC (1200LST), Jan. 19, 2001. In this case, the air parcels spend most of the 72 hours over industrial areas of China before traveling to Taiwan. During three days of travel, the air parcels of 100, and $500 \mathrm{~m}$ are mostly at relatively low altitude (below $1000 \mathrm{~m}$ ). So the probability of picking up air pollutants over industrial areas for these air parcels should be relatively high. 

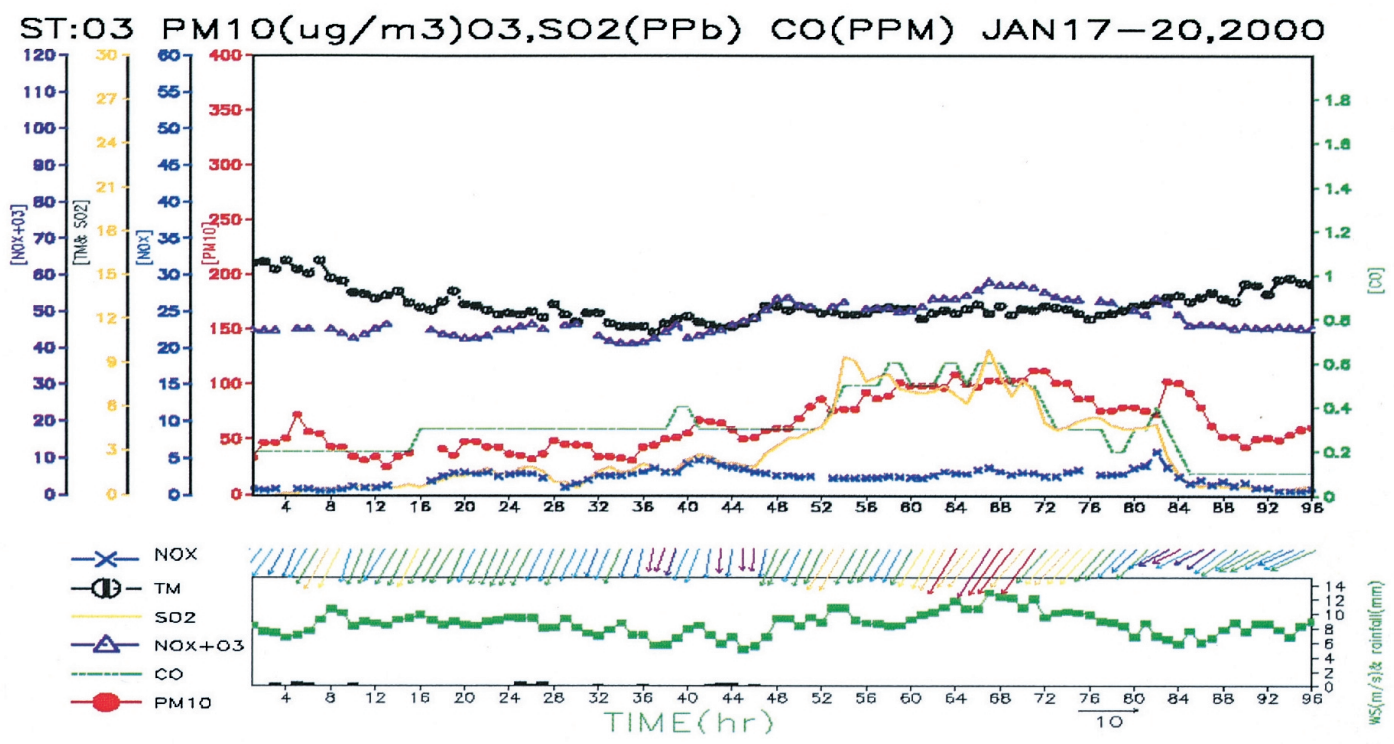

Fig. 11. The time series of hourly $\mathrm{PM}_{10}$ (red closed circles), $\mathrm{CO}$ (dashed line), $\mathrm{SO}_{2}$ (solid), $\mathrm{NO}_{\mathrm{X}}+\mathrm{O}_{3}$ (triangle), $\mathrm{NO}_{\mathrm{X}}$ (cross), surface temperature (open circle with vertical line), wind speed (closed square, bottom panel) and rainfall (black bar, bottom panel) are shown at Wan-Li station during a frontal pollution case (0100LST Jan. 17 to 2400LST Jan. 20, 2000). Surface wind at Wan-Li station is represented by wind vector.

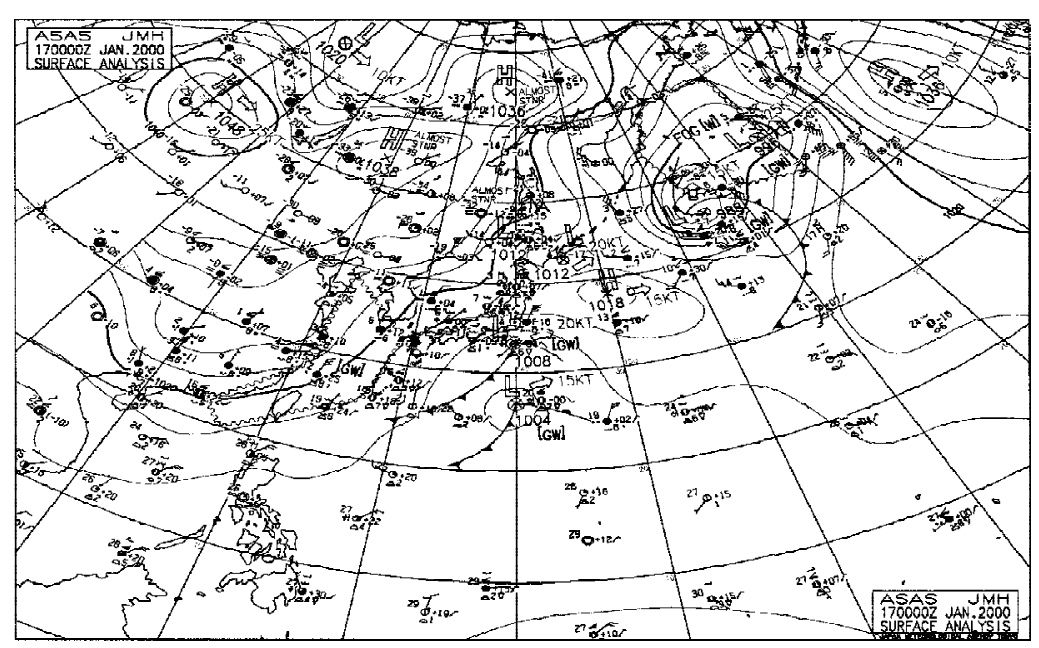

Fig. 12. Synoptic-scale surface analysis at 0000Z (0800LST) Jan. 17, 2000. 
(a) ST:64 PM1O(ug/m3)03,SO2(PPb) CO(PPM) JAN17-20,2000
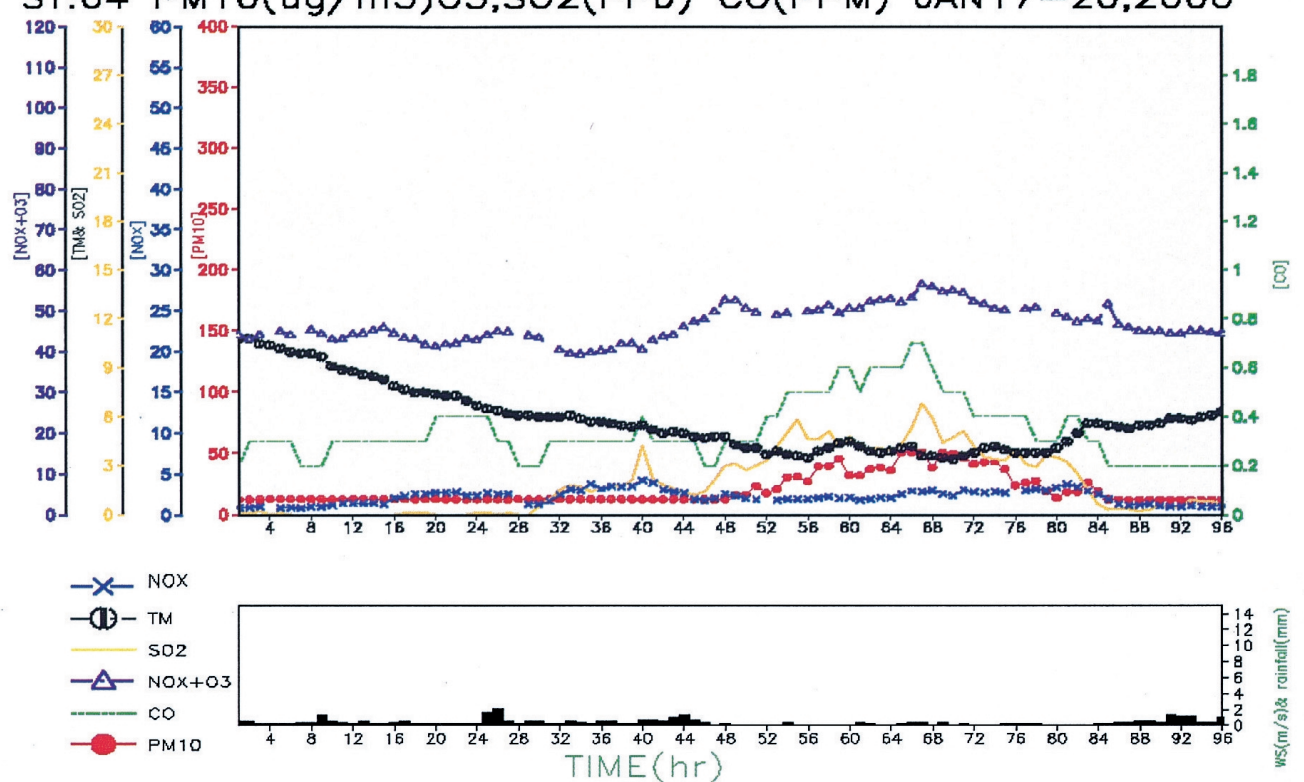

(b)
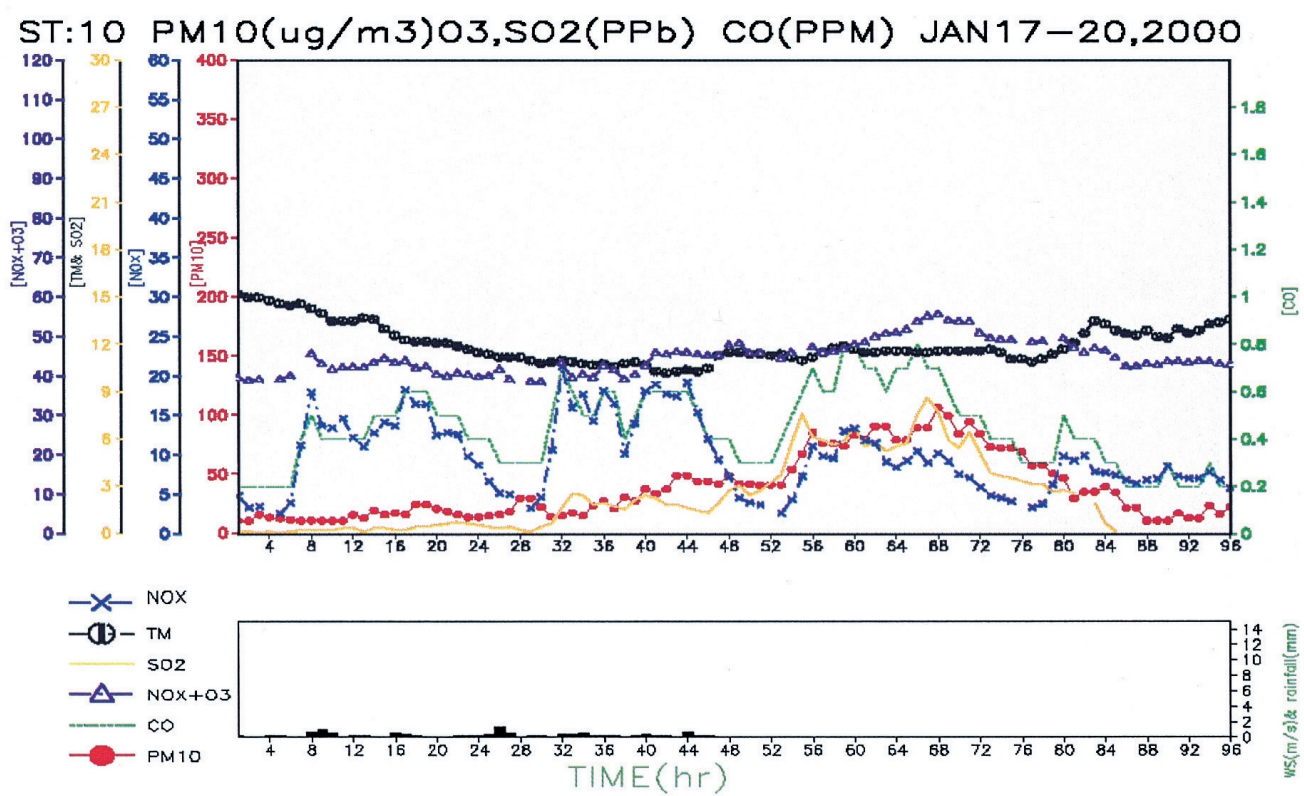

Fig. 13. The time series of hourly $\mathrm{PM}_{10}$ (red closed circles), $\mathrm{CO}$ (dashed line), $\mathrm{SO}_{2}$ (solid), $\mathrm{NO}_{\mathrm{X}}+\mathrm{O}_{3}$ (triangle), $\mathrm{NO}_{\mathrm{X}}$ (cross), surface temperature (open circle with vertical line), wind speed (closed square, bottom panel) and rainfall (black bar, bottom panel) are shown at (a) Yang-Ming station (b) Tan-Shui station during a frontal pollution case (0100LST Jan. 17 to 2400LST Jan. 20, 2000). 


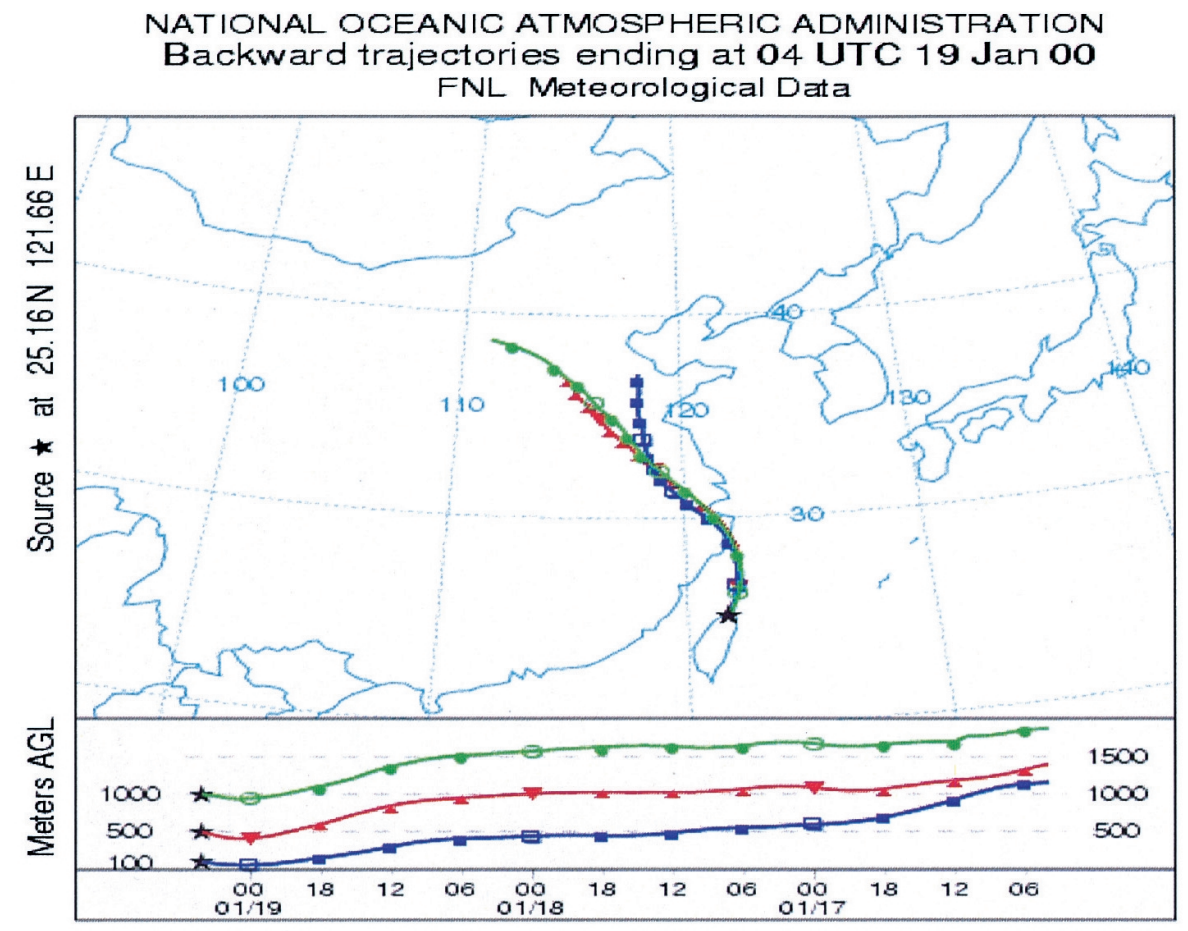

Fig. 14. Result of the HYSPLIT model 3-day backward trajectory analysis started at 0400UTC (1200LST), Jan. 19, 2000 at altitudes of 100, 500 and $1000 \mathrm{~m}$ at Wan-Li station in northern Taiwan. The top and bottom panels display horizontal and vertical motion. Symbols denote the location of the air parcel every 6 hours.

\subsubsection{Background Air Masses}

Figure 15 shows the front passing over northern Taiwan was nearly stationary on the morning of Feb. 10, 2001 and exhibited typical characteristics of a northeasterly monsoon. Concentrations of $\mathrm{PM}_{10}, \mathrm{NO}_{\mathrm{X}}, \mathrm{CO}$, and $\mathrm{SO}_{2}$ during this period were relatively low on both Feb. 9 and 10 (Fig. 16a). For example, $\mathrm{PM}_{10}$ concentrations never exceeded $50 \mu \mathrm{g} \mathrm{m}^{-3}$ at Wan-Li (Fig. 16a), Yang-Ming (Fig. 16b) and Tan-Shui (Fig. 16c). Apparently the northeastern winter monsoon brought a relatively clean background air mass from the East China Sea into northern Taiwan. This air mass is denoted as BG.

Figure 17 shows that the relatively clean background air parcel traveled from northeastern China and moved southeastward to Taiwan on Feb. 10, 2001, mostly over the ocean. Other than spending a long time over the ocean, this case was accompanied by abundant precipitation. 


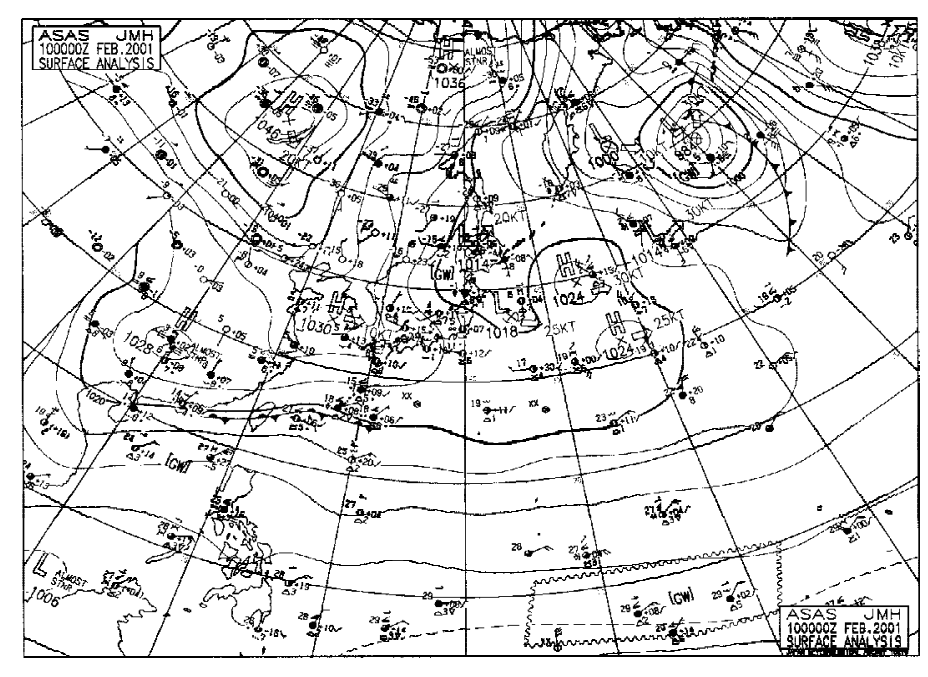

Fig. 15. Synoptic-scale surface analysis at 0000Z (0800LST) 10 Feb. 2001.

Effective wet and dry deposition may account for the low average concentrations of air pollutants for the BG case. Nevertheless, $\mathrm{CO}$ which is not water soluble and thus not subject to wet deposition or dry deposition to the ocean was also low.

Based on the classification method described above, most of the long-range transport episodes can be easily separated. However, the method also has limitations. For example, once the surface pressure gradient and wind speed declines after frontal passage, local emission influences become more evident. In this situation, although the air mass still has a significant contribution from long-range transport the case remains classified as an LP case. This is particularly so when the concentrations of long-range transport dust or pollutants are not very high, e.g., BG cases. In this regard, since frequency of frontal passages is about once a week (Bachmeier et al. 1996), comparable to the lifetime of $\mathrm{PM}_{10}$, one can expect long-range transport to have a significant "legacy" contribution to an LP case that follows a frontal passage. This has important implications for the evaluation of long-range transport on Taiwan's air quality as is elaborated on later.

It is important to note that the lower atmosphere of the East China Sea in winter and spring is generally polluted as a result of frequent (once a week) northeasterly winter monsoons bringing Asian continental air to this area. This has been substantiated by extensive measurements during PEM-West B (Hoell et al. 1997), BIBLE (Kondo et al. 2003), TRACE$P$ (Jacob et al. 2003), and ACE-Asia (Huebert et al. 2003) experiments that showed significant anthropogenic pollutants in the boundary layer over the East China Sea. In addition, satellite observations also show widespread distributions of high aerosol optical depth in the western North Pacific in winter and spring as a result of Asian continental outflow (Husar et al. 2001; Nakajima et al. 2003). Therefore the background air of the East China Sea is likely to be 
(a)

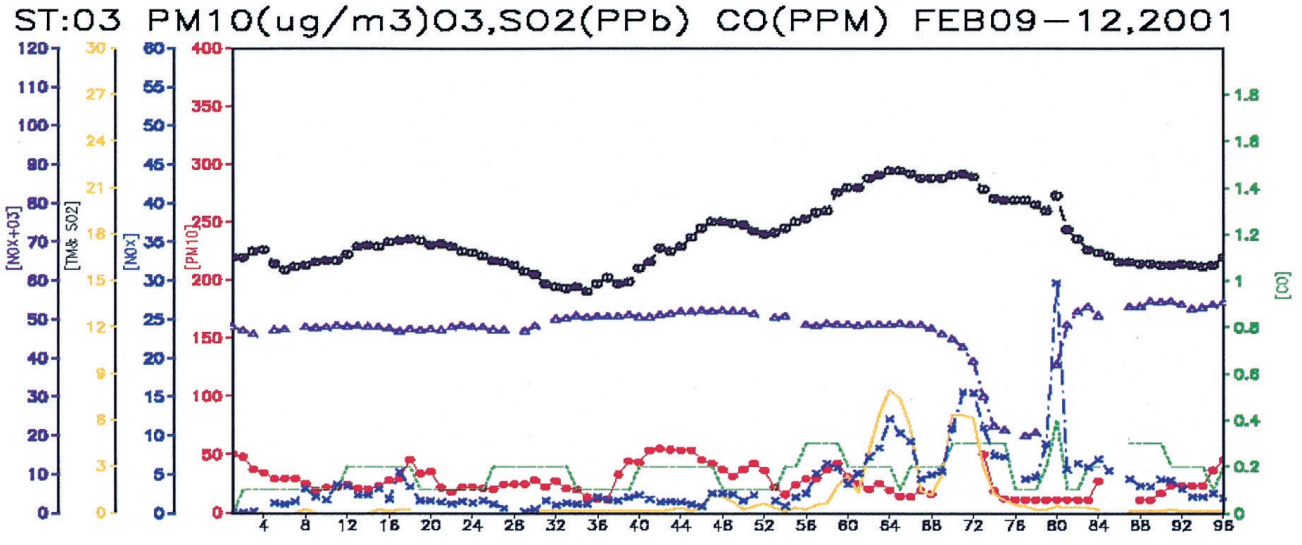

(b)
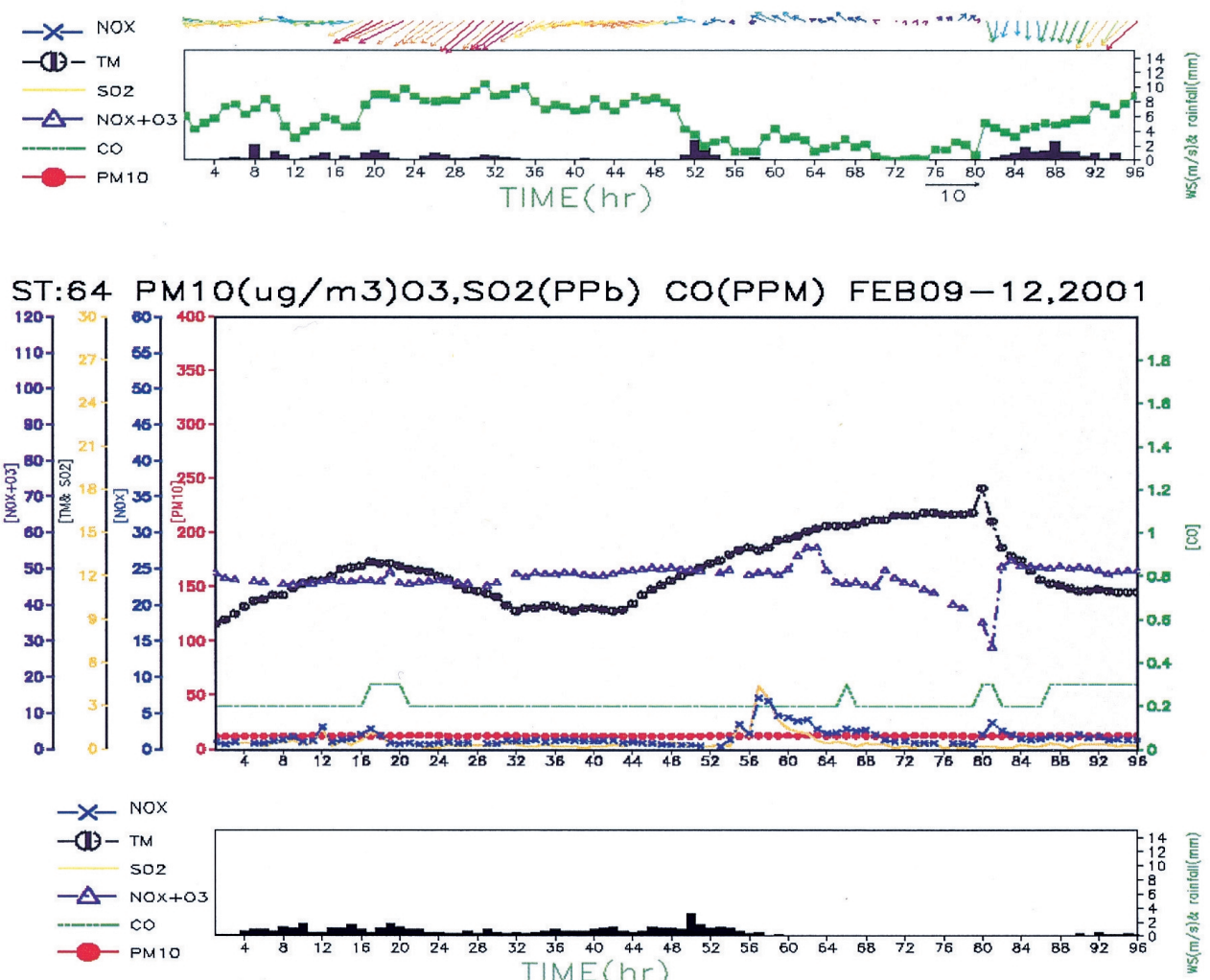

Fig. 16. The time series of hourly $\mathrm{PM}_{10}$ (red close circles), $\mathrm{CO}$ (dashed line), $\mathrm{SO}_{2}$ (solid), $\mathrm{NO}_{\mathrm{X}}+\mathrm{O}_{3}$ (triangle), $\mathrm{NO}_{\mathrm{X}}$ (cross), surface temperature (open circle with vertical line), wind speed (closed square, bottom panel) and rainfall (black bar, bottom panel) are shown at (a) Wan-Li station (b) Yang-Ming (c) Tan-Shui during a frontal clean case (0100LST 9, Feb. to 2400LST 12 Feb. 2001). Surface wind at Wan-Li station is represented by wind vector. 
(c)

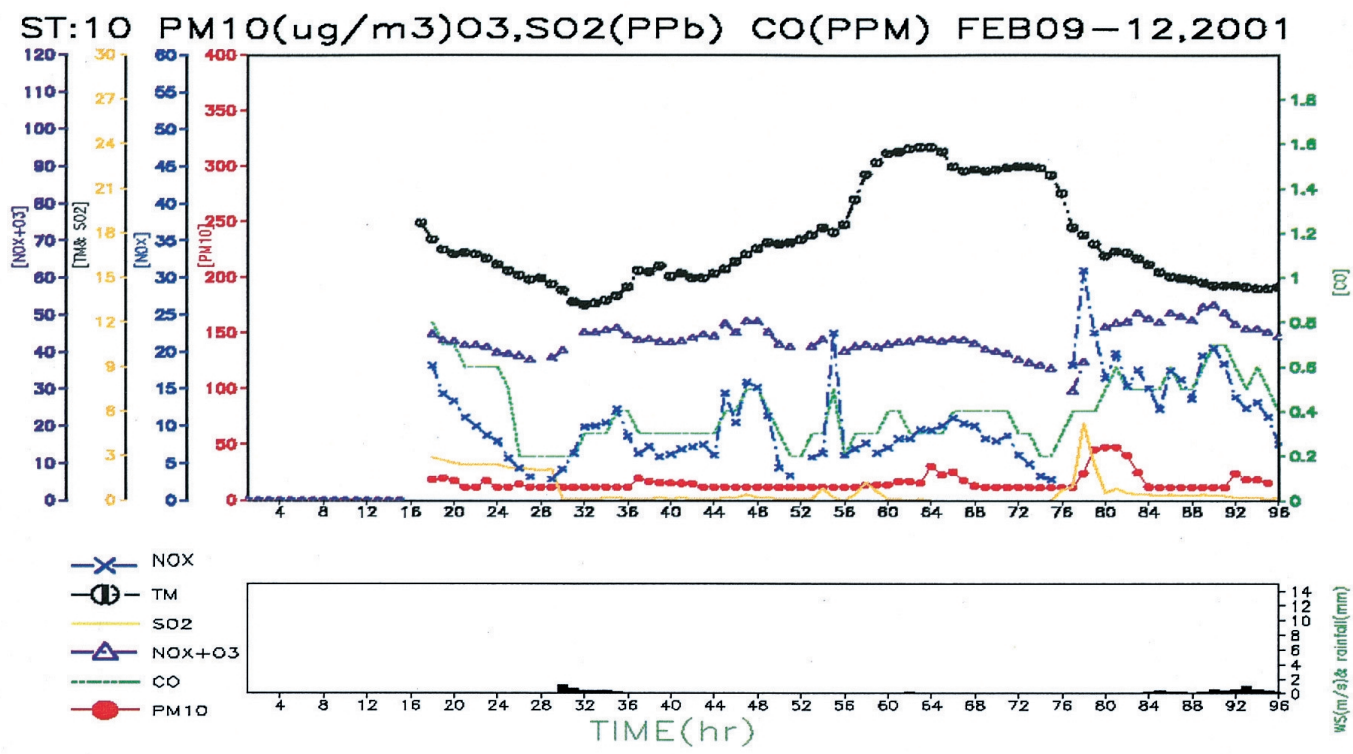

Fig. 16. Continued (data missing during 01 18 LST 09 Feb. 2001).

significantly polluted due to outflows from the Asian continent. Furthermore, in the boundary layer, strong turbulence mixing results in well-mixed polluted background air prevailing. This well-mixed polluted background air is most likely the BG cases observed in Taiwan. This is supported by our own measurements that show that more than half of the $32.8 \mu \mathrm{g} \mathrm{m}^{-3}$ of $\mathrm{PM}_{10}$ are sulfate, nitrate, and ammonium ions, soot and organic carbon. In conclusion, all three frontal passage cases, i.e., DS, FP, and BG, ought be considered long-range transport cases of Asian continental air masses onto northern Taiwan. This is so even for BG cases which have lower concentrations of $\mathrm{PM}_{10}$ (i.e., cleaner) than those of the LP cases.

\section{IMPACT OF LONG-RANGE TRANSPORT ON AIR QUALITY}

Applying the method developed in Section 4, we can evaluate the frequency of occurrence of each case and use it to estimate the impact on the air quality of Taiwan. Table 1 shows frequency of occurrence for local pollution and three long-range transport cases during the winters and springs of a two-year period (Nov. 1999 to May 2000 and Nov. 2000 to May 2001). Crosschecking against other years has confirmed that the two years are representative of the other ten years TEPA has maintained the current extensive network of stations.

The average $\mathrm{PM}_{10}$ concentration of local pollution (LP) cases at the Wan-Li station is about $47.4 \mu \mathrm{g} \mathrm{m}^{-3}$. The frequency of occurrence of LP cases in these two years is $71.7 \%$ or 305 days out of 14 months. Dust storm (DS) cases occur 4.7\% of the time or 20 days in 14 


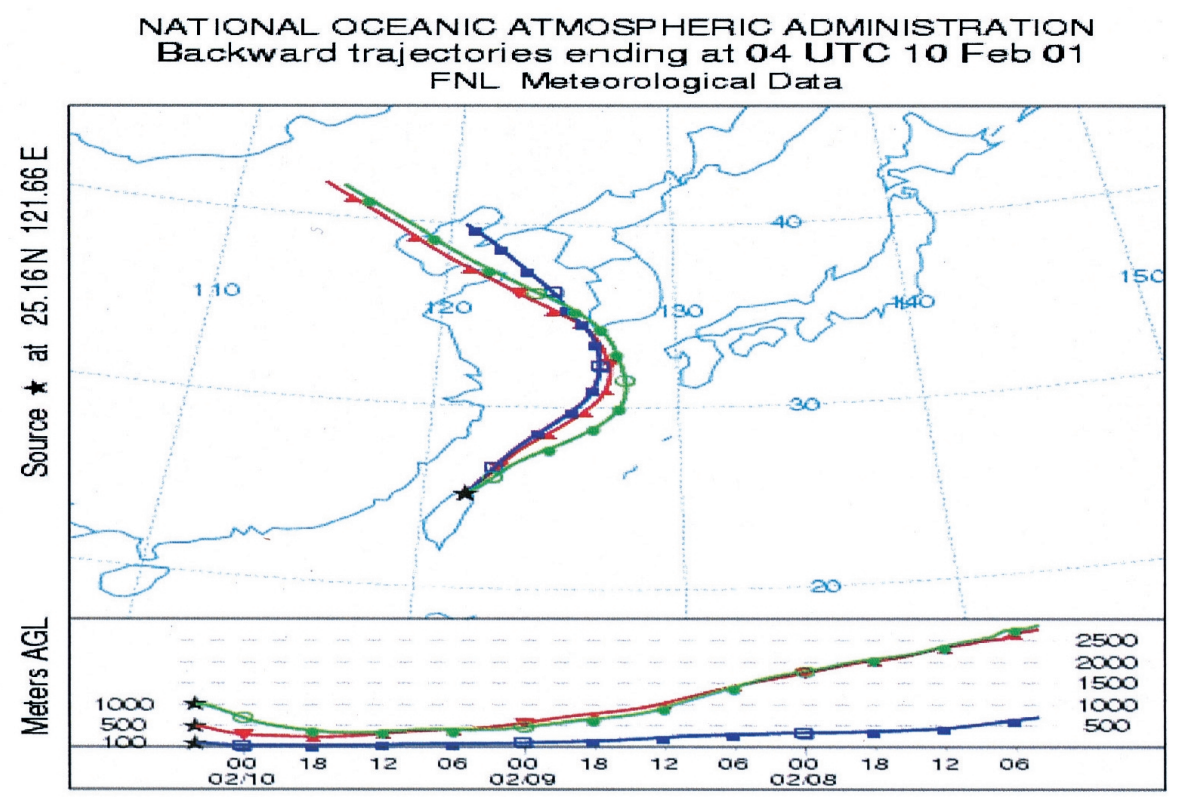

Fig. 17. Result of the HYSPLIT model 3-day backward trajectory analysis started at 0400UTC (1200LST), Feb 10, 2001 at altitudes of 100, 500 and 1000 $\mathrm{m}$ at Wan-Li station in northern Taiwan. The top and bottom panels display horizontal and vertical motion. Symbols denote the location of the air parcel every 6 hours.

months and have a large average $\mathrm{PM}_{10}$ concentration of $127.6 \mu \mathrm{g} \mathrm{m}^{-3}$ at Wan-Li station. Since an average dust storm event lasts 2 days, we get $5 \%$ per year as the frequency of occurrence for the DS, a very reasonable number. Frontal pollution cases (FP) occur about $1.9 \%$ of the time or 8 days and the mean concentration of $\mathrm{PM}_{10}$ during the FP periods is about $85 \mu \mathrm{g} \mathrm{m}^{-3}$. Background frontal cases (BG) happen $18.6 \%$ of the time or 79 days and the mean concentration of $\mathrm{PM}_{10}$ is $32.8 \mu \mathrm{g} \mathrm{m}^{-3}$. So the long-range transport cases (i.e., sum of DS, FP, and BG) occur approximately $25 \%$ of the time or 107 days with an average concentration of $54.4 \mu \mathrm{g} \mathrm{m}^{-3}$. Assuming again 2 days per frontal passage, we get about 54 cold fronts over 14 months which are very close to the climatological average of one per week frequency suggested by Bachmeier et al. (1996). This also substantiates the representativeness of the two years.

We notice, however, that the number of BG cases (about 40 cases) is much greater than the number of FP cases (about 4 cases). In addition, in terms of levels of gas phase air pollutants the DS cases resemble closer those of BG cases than FP cases. Given the fact that nearly all cold fronts pass over polluted areas of the Asian continent within 5 days prior to reaching Taiwan, it is surprising to see so few FP cases. Two processes may contribute to this 
Table 1. The percentage and average concentration of local pollution (LP), dust storm (DS), Background air masses (BG), frontal pollution (FP), and data missing (M) cases are shown at Wan-Li station in the two-year period (Nov. 1999 to May 2000 and Nov. 2000 to May 2001).

\begin{tabular}{|c|c|c|c|c|c|}
\hline & LP & DS & FP & BG & M \\
\hline $1999 / 11$ & $\mathbf{2 5}$ & 0 & $\mathbf{1}$ & 0 & 4 \\
\hline $1999 / 12$ & $\mathbf{2 1}$ & 0 & $\mathbf{2}$ & 5 & 3 \\
\hline $2000 / 01$ & $\mathbf{1 7}$ & 0 & $\mathbf{5}$ & 9 & 0 \\
\hline $2000 / 02$ & $\mathbf{1 3}$ & 3 & $\mathbf{0}$ & 13 & 0 \\
\hline $2000 / 03$ & $\mathbf{2 5}$ & 3 & $\mathbf{0}$ & 3 & 0 \\
\hline $2000 / 04$ & $\mathbf{2 2}$ & 3 & $\mathbf{0}$ & 5 & 0 \\
\hline $2000 / 05$ & $\mathbf{2 9}$ & 1 & $\mathbf{0}$ & 1 & 0 \\
\hline $2000 / 11$ & $\mathbf{1 8}$ & 0 & $\mathbf{0}$ & 11 & 1 \\
\hline $2000 / 12$ & $\mathbf{1 7}$ & 0 & $\mathbf{0}$ & 11 & 3 \\
\hline $2001 / 01$ & $\mathbf{2 5}$ & 2 & $\mathbf{0}$ & 4 & 0 \\
\hline $2001 / 02$ & $\mathbf{1 9}$ & 2 & $\mathbf{0}$ & 7 & 0 \\
\hline $2001 / 03$ & $\mathbf{2 6}$ & 2 & $\mathbf{0}$ & 3 & 0 \\
\hline $2001 / 04$ & $\mathbf{2 5}$ & 3 & $\mathbf{0}$ & 2 & 0 \\
\hline $2001 / 05$ & $\mathbf{2 3}$ & 1 & $\mathbf{0}$ & 5 & 2 \\
\hline Total (days) & $\mathbf{3 0 5}$ & 20 & $\mathbf{8}$ & 79 & 13 \\
\hline$\% \%$ & $\mathbf{7 1 . 7}$ & 4.7 & $\mathbf{1 . 9}$ & 18.6 & 3.1 \\
\hline Average ( $\mu \mathrm{g} / \mathrm{m} 3)$ & $\mathbf{4 7 . 4}$ & 127.6 & $\mathbf{8 5}$ & 32.8 & \\
\hline & & & & & \\
\hline
\end{tabular}

phenomenon, one is that the air parcel passes above the polluted area without picking up any significant amount of pollutants, another is that the pollutants are diluted to BG levels during long-range transport. In regard to the latter we note that, as discussed earlier, turbulent mixing or dilution is highly efficient in the boundary layer over the East China Sea because of the cold winter monsoon over the relatively warm Kuroshio Current.

Based on the discussion above, it is tempting to make an obvious conclusion that the contribution to the total $\mathrm{PM}_{10}$ for Wan-Li station in winter and spring is about $70 \%$ (Table 1) from local emissions (LP) and 30\% from the long-range transport (DS + FP + BG). This conclusion, however, is subject to the assumption that DS, FP, and BG are entirely due to 
long-range transport and LP is solely from local emissions. We know the latter assumption is false because of the "legacy" effect discussed in Section 4. Moreover, the assumption that DS, FP, and BG are entirely due to the long-range transport is only qualitatively correct. There should be a finite contribution of local emissions during all frontal passage cases. Northeasterly winds can blow away some, but not all local emissions. We have made an estimate of this effect by examining the BG cases at all stations in northern Taiwan. By comparing stations with different emission rates, we estimate that the contribution of local emissions during a typical frontal passage case is less than $10 \mu \mathrm{g} \mathrm{m}^{-3}$ in northern Taiwan. For Wan- $\mathrm{Li}$, it is about $5 \mu \mathrm{g} \mathrm{m}^{-3}$, a negligible value. The "legacy" effect, however, can be substantial. Assuming a nominal lifetime of $\mathrm{PM}_{10}$ of about 5 days and one frontal passage per week (Bachmeier et al. 1996), approximately half of the $\mathrm{PM}_{10}$ from a frontal passage can be present during the trailing LP episode. This means that about half of the $\mathrm{PM}_{10}$ concentrations of LP cases are due to long-range transport. The uncertainty in the estimate of the "legacy" effect is about 2, i.e., one to two-thirds of the $\mathrm{PM}_{10}$ concentrations of LP cases are due to long-range transport. When this is taken into account, we estimate that the contribution of the long-range transport to $\mathrm{PM}_{10}$ abundance at Wan-Li station in winter and spring is in the range of 50\% to $75 \%$, the rest being from local emissions.

We have examined data at other stations in northern Taiwan and found that the $50 \%$ and $75 \%$ range applies to most stations, including stations in most urban areas. The contribution of long-range transport can increase up to $80 \%$ at some clean rural stations and decrease to as low as $35 \%$ at highly polluted urban stations. The value reaches nearly $100 \%$ at a station on the Penghu Islands. The fact that the $\mathrm{PM}_{10}$ concentrations at the Penghu station had an average value of about $50 \mu \mathrm{g} \mathrm{m}^{-3}$ and rarely got below $25 \mu \mathrm{g} \mathrm{m}^{-3}$ in winter and spring was consistent with the discussions above, particularly in regard to the average concentration of long-range transport cases $\left(54.4 \mu \mathrm{g} \mathrm{m}^{-3}\right)$ and the legacy effect. In summer and fall, the average $\mathrm{PM}_{10}$ concentration at the Penghu station is about $20 \mu \mathrm{g} \mathrm{m}^{-3}$.

The contribution of long-range transport to $\mathrm{PM}_{10}$ abundance in the range of 50\% to $75 \%$ in northern Taiwan is a remarkably high value. It obviously has important implications for control strategies of air pollution over northern Taiwan. For example, local emission control can only affect less than half of the abundance of $\mathrm{PM}_{10}$ in the region. In southern Taiwan, reductions in local emissions should be more effective as the Central Mountain Range weakens the northeasterly winter monsoon. At this moment we don't have a quantitative estimate of the contribution of long-range transport to $\mathrm{PM}_{10}$ abundance in southern Taiwan. The method developed above has too much uncertainty to give a reliable estimate. Model calculations are needed.

Chang et al. (2000) made a model study based on TAQM (Taiwan Air Quality Model; Chang (1990) to understand the impact of long-range transport on acid deposition in Taiwan under various weather conditions. They found that about $45 \%$ of the total deposition (dry and wet depositions) of sulfate in Taiwan was the result of long-range transportation during a northeasterly monsoon episode. Their calculations also showed approximately a 2 to 1 ratio for northern vs. southern Taiwan contributions. This means $60 \%$ of the total deposition of sulfate in Taiwan was contributed by long-range transport during a northeasterly monsoon episode, and 30\% for southern Taiwan. Although strictly speaking, sulfate deposition can't be 
compared directly to the $\mathrm{PM}_{10}$ concentration, the agreement between the $60 \%$ value in northern Taiwan with our range of $50 \%$ to $75 \%$ is reassuring. In this regard, we notice that an analysis of the measurements of acid precipitation in Taipei by Lin et al. (1999) also suggested a dominant role for long-range transport.

Using the same method, we estimate that the range of $50 \%$ to $75 \%$ contribution of longrange transport to $\mathrm{PM}_{10}$ abundance in northern Taiwan is also applicable to other air pollutants with relatively long lifetimes, e.g., $\mathrm{CO}$ and ozone. For short-lived species such as $\mathrm{NO}_{\mathrm{X}}$ and $\mathrm{SO}_{2}$, contributions from long-range transport to their abundances in Taiwan ought be substantially smaller for two reasons: first there is significant loss during long-range transport, and second there shorter life spans means that their contribution to the "legacy effect" ought be smaller. We plan to make a study of contribution dependency due to species lifetimes in a separate paper.

\section{SUMMARY AND CONCLUSIONS}

Taiwan is an island in the subtropics, located off the southeast coast of mainland China. During winter and spring, as part of the winter Asian monsoon, the Siberian high dominates the weather pattern of East Asia. Dust storms generated in arid areas of central Asia usually follow the track of anticyclones southeastward behind a cold front. The passage of a cold front over Taiwan is characterized by a rapid drop in surface temperature and a shift to strong northeasterly winds which can transport dust and air pollutants from the Asian continent onto Taiwan.

Back trajectory analysis of a typical dust storm (Fig. 1) that influenced Taiwan showed that its trajectories started at relatively high altitudes (above $3 \mathrm{~km}$ ) over desert regions in western China and subsided under the control of a high-pressure system on its long-range transport to Taiwan (Fig. 1). The trajectories passed over polluted regions of the Asian continent and could have picked up air pollutants if the vertical mixing was effective. In this work, we have studied the processes of long-range transport of dust and air pollutants by examining the temporal and spatial distributions of aerosols and trace gases during various phases of the frontal passage. More importantly, we have made an estimate of the impact of long-range transport of $\mathrm{PM}_{10}$ on the air quality in northern Taiwan.

Stagnant and sunny conditions are typical prior to the frontal passage in Taiwan. Under these conditions local emissions are a major source of air pollutants. Concentrations of air pollutants consistently show temporal variations with peaks around rush hour. These cases are classified as local pollution (LP).

The strong northeasterly winds behind the cold front sweep away most of the local pollutants and replace them with air parcels that can be backtracked usually to the Asian continent. Based on measurements of $\mathrm{PM}_{10}$ and other air pollutants at the TEPA air quality ground stations, we have shown that the long-range transport associated with frontal passages can be further classified into three types: (1) the dust storm case (DS) that consists primarily of Asian mineral dust but not necessarily air pollutants; (2) the frontal pollution case (FP) that contains a significant amount of air pollutants from the Asian continent but little dust; and (3) the 
background air case (BG) that contains relatively clean background air from the East China Sea.

Essentially no correlation is found between dust and air pollutants observed at TEPA air quality monitoring stations. In fact, dust and air pollutants are usually transported in separate air parcels. This is the case despite most dust storms passing over polluted areas of the Asian continent. Obviously vertical mixing conditions are usually not favorable for entrainment of air pollutants into the dust storms.

We have analyzed the frontal passages over two representative years and obtained the following results. DS cases occur $4.7 \%$ of the time and have a large average $\mathrm{PM}_{10}$ concentration of $127.6 \mu \mathrm{g} \mathrm{m}^{-3}$ at Wan-Li station. Frontal pollution cases (FP) occur $1.9 \%$ of the time and the mean concentration of $\mathrm{PM}_{10}$ during the FP periods is about $85 \mu \mathrm{g} \mathrm{m}^{-3}$. Background frontal cases (BG) happen $18.6 \%$ of the time and the mean concentration of $\mathrm{PM}_{10}$ is about $32.8 \mu \mathrm{g} \mathrm{m}^{-3}$. So long-range transport cases occur approximately $25 \%$ of the time (i.e., sum of DS, FP, and BG) with an average concentration of $54.4 \mu \mathrm{g} \mathrm{m}^{-3}$. The frequency of occurrence of $\mathrm{LP}$ cases is $71.7 \%$ in winter and spring. The average $\mathrm{PM}_{10}$ concentration of LP cases at the Wan-Li station is $47.4 \mu \mathrm{g} \mathrm{m}^{-3}$.

There was about one frontal passage per week, consistent with the climatological average (Bachmeier et al. 1996). The short interval of about five days (i.e., LP cases) in between two frontal passages is approximately equal to the lifetime of $\mathrm{PM}_{10}$. This means that a significant amount of $\mathrm{PM}_{10}$ during the frontal passage will be present in the trailing LP period. We estimate about one-third to two-thirds of the $\mathrm{PM}_{10}$ of LP cases is contributed by this "legacy" effect of long-range transport. When this effect is taken into account, we estimate that the contribution of the long-range transport to $\mathrm{PM}_{10}$ in northern Taiwan in winter and spring is in the range of $50 \%$ to $75 \%$. These values are remarkably large and have important implications for control strategies. We believe that the range also applies to other air pollutants with relatively long lifetimes, e.g., $\mathrm{CO}$ and ozone. For short-lived species such as $\mathrm{NO}_{\mathrm{X}}$ and $\mathrm{SO}_{2}$, contributions of long-range transport to their abundances in Taiwan should be substantially smaller.

Acknowledgments This work is supported by a grant from Academia Sinica under theme project "Particulate Matter and its Environmental Impact in Taiwan". We would like to thank the Environmental Protection Administration, Taiwan, ROC for providing the ground station data. The authors gratefully acknowledge the NOAA Air Resources Laboratory (ARL) for the provision of the HYSPLIT transport and dispersion model and READY website (http://www. arl.noaa.gov/ready.html) used in this publication.

\section{REFERENCES}

Akimoto, H. et al., 1996: Long-range transport of ozone in the East Asian Pacific Rim region. J. Geophys. Res., 101, 1999-2010.

Bachmeier, A. S., R. E. Newell, M. C. Shipham, Y. Zhu, D. R. Blake, and E. V. Browell, PEM-West A, 1996: Meteorological overview.J. Geophys. Res., 101, 1655-1677. 
Chang, K. H., F. T. Jeng, Y. L. Tsai, and P. L. Lin, 2000: Modeling of long-range transport on Taiwan's acid deposition under different weather conditions. Atmos. Environ., 34, 32813295.

Chang, J. S. (principal author), 1990: The regional acid deposition model and engineering model. Acidic Deposition: State of Science and Technology Report 4, National Acid Precipitation and Assessment program, Washington, DC. 130pp.

Chen, T. J., and H. J. Chen, 1987: Study on large-scale features of dust storm system in East Asia. Meteorol. Res., 10, 57-79.

Chun, Y. S., K. O. Boo, K. Kim, S. U. Park, M. Lee, and Synopsis, 2001: Transport, and physical characteristics of Asian dust in Korea. J.Geophys. Res., 106, 18461-18469.

Duce, R. A. , C. K. Unni, B. J. Ray, J. M. Prospero, and J. T. Merrill, 1980: Long-range atmospheric transport of soil dust from Asia to the tropical North Pacific: Temporal variability. Science, 209, 1522-1524.

Draxler, R. R., and G. D. Hess, 1998: An overview of the Hysplit-4 modeling system for trajectories, dispersion, deposition. Aust. Meteorol. Mag., 47, 295-308.

Lin, N. H, H. M. Lee, and M. B. Chang, 1999: Evaluation of the characteristics of acid precipitation in Taipei, Taiwan using cluster analysis. Water, Air, and Soil Pollut., 113, 241-260.

Liu, S. C., and C. J. Shiu, 2001: Asian dust storms and their impact on the air quality of Taiwan. Aerosol Air Quality Res., 1,1-8.

Lin, T. H., 2001: Long-range transport of yellow sand to Taiwan in spring 2000: Observed evidence and simulation. Atmos. Environ., 35, 5873-5882.

Harris, J. M., P. P. Tans, E. J. Dlugokencky, K. A. Masarie, P. M. Langs, S. Whittlestone, and L. P. Steele, 1992: Variations in atmospheric transport climatology for the Mauna Loa observatory, using clustered trajectories. J. Geophys. Res., 97, 6003-6010.

Higurashi, A., and T. Nakajima, 2002: Detection of aerosol types over the East China Sea near Japan from four-channel satellite data. Geophys. Res. Lett., 29, 1836, doi: 10. 1029/2002GL015357.

Hoell, J. M. et al., 1997: The Pacific exploratory Mission-West Phase B: Febriary-March 1994. J. Geophys. Res., 102, 28223-28239.

Huebert, B. J. et al., 2003: An overview of ACE-Asia: Strategies for quantifying the relationships between Asian aerosols and their climatic impacts. ACE-Asia special issue A.J. Geophys. Res., 108, 8633, doi: 10.1029/2003JD003550.

Husar R. B. et al., 2001: The Asian dust events of April 1998.J. Geophys. Res., 106,1831718330.

Jacob, D. J. et al., 2003: Transport and chemical evolution over Pacific (TRACE-P) aircraft mission: Design, execution, and first result. J. Geophys. Res., 108, NO (D20), doi: 10. 1029/2002JD003276.

Jaffe, D. A., A. Mahura, J. Kelley, J. Atkins, P.C. Novelli, and J. Merrill, 1997: Impact of Asian emissions on the remote North Pacific atmostphere: Interpretation of CO data from Shemya, Guam, Midway, and Mauna Loa.J. Geophys. Res., 102, 28627-28636. 
Kondo,Y., M. Ko, M. KiKe, S. Kawakami, and T. O. Gawa, 2003: Preface to special section on Biomass burning and lightning experiment (BIBLE).J. Geophys. Res., 108, doi: 10. 1029/2002JD002401.

Murayama, T., et al., 2001: Ground-based network observation of Asian dust eveint of April 1998 in east Asia. J.Geophys. Res., 106, 18345-18359.

Nakajima, T. et al., 2003: Significance of direct and indirect radiative forcings of aerosols in the East China Sea region. J.Geophys. Res., 108, 8658, doi: 10.1029/2002JD003261.

Okada K. et al., 1990: X-ray spectrometry of individual Asia dust-storm particles over the Japanese Islands and the North Pacific Ocean. Atmos. Envrion., 24, 1369-1378.

Parrington, J. R., W. H. Zoller, N. K. Aras, 1983: Asian dust:Seasonal transport to Hawaiian islands. Science, 220, 195-197.

Prospero, J. M., D. L. Savoie, and R. A. Arimoto, 2003: Long-term record of nss-sulfate and nitrate in aerosols on Midway Island, 1981-2000: Evidence of increased (now decreasing ?) anthropogenic emissions from Asia.I. Geophys. Res., 108(D1), 4019, doi: 10. 1029/2001JD001524.

Prospero, J. M., D. L. Savoie, R. T. Nee, R. A. Duce, and J. Merrill, 1985: Particulate sulfate and nitrate in the boundary layer over the North Pacific Ocean.J. Geophys. Res., 90 10586-10596.

Prospero, J. M., and D. L. Savoie, 1989: Effect of continental sources of nitrate concentrations over the Pacific Ocean. Nature, 339, 687-689.

Shaw, G. E., 1980: Transport of Asian desert aerosol to Hawaiian Islands.J. Appl. Meteorol., 19, 1254-1259.

Shu, S. C., S. C. Liu, C. Y. Lin, R. T, Hsu, Y. T. Huang, and Y. W. Chen, 2004: Metal Compositions of characterizations of $\mathrm{PM}_{10}$ and $\mathrm{PM}_{2.5}$ Aerosols in Taipei during spring, 2002. TAO, 15, 925-948.

Smirnov, A., B. Holben, D. Savoie, J. Prospero, Y. Kaufman, D. Tanre, T. Eck, and I. Slutsker, 2000: Relationship between column aerosol optical thickness and in situ ground based dust concentration over Barbados. Geophys. Res. Lett., 27, 1643-1646.

Uematsu, M., R. A. Duce, J. M. Prospero, L. Chen, J. T. Merrill, and R. L. McDonald, 1983: Transport of mineral aerosol from Asia over the North Pacific Ocean.J.Geophys. Res., 88, 5343-5352.

Uematsu, M., T. Sugita, V. V. Anikiev, and A. N. Medvedev, 1992: Large-scale transport of pollution aerosol over the East Coast of Asia. Geophys, Res. Lett., 19, 2219-2221.

Uematsu, M., A. Yoshikawa, H. Muraki, K. Arao, and I. Uno, 2002: Transport of mineral and anthropogenic aerosols during a Kosa event over East Asia.J. Geophys. Res., 107(D7), 4059, doi: 10.1029/2001JD000333.

Uno, I. , H. Amano, S. Emori, K. Kinoshita, I. Matsui, and N. Sugimoto, 2001: Trans-Pacific yellow sand transport observed in April 1998: A numerical simulation.J. Geophys. Res., 106, 18331-18334.

Uno, I. et al., 2003: Regional chemical weather forecasting system CFORS: Model description and analysis of surface observations at Japanese island stations during the ACEAsia experiment. J. Geophys. Res., 108, 8668, doi: 10.1029/2002JD002845. 
Wan M. X., J. W. Winchester, T. A. Cahill, and L. X. Ren, 1982: Chmical elemental composition of windblown dust, Beijing. Кехие Tongbao, 27, 1193-1198.

Wang, S. T., 1974 : On the formation and development of polar anticyclones over Asia and the extended forecasting of cold air surges in Taiwan. Research Report No.007, The Weather Central, Weather Wing, CAF, Taipei (in Chinese with English abstract).

Wang, C. C., C. T. Lee, S. C. Liu, and J. P. Chen, 2004: Aerosol Characterization at Taiwan's Northern Tip during ACE-Asia. TAO, 15, 839-855.

Wang, Z., H. Ueda, and M. Huang, 2000: A deflation module for use in modeling long-range transport of yellow sand over East Asia. J. Geophys. Res., 105, 26947-26960.

Xiao, H., G. R. Carmichael, J. Durchenwald, D. Thornton, and A. Bandy, 1997: Long-range transport of Sox and dust in East Asia during the PEM B experiment.J. Geophys. Res., 102, 28589-28612. 